\title{
Local versus Tropical Diabatic Heating and the Winter North Atlantic Oscillation
}

\author{
RichaRD J. GREATBATCH \\ Department of Oceanography, Dalhousie University, Halifax, Nova Scotia, Canada \\ THOMAS JUNG \\ European Centre for Medium-Range Weather Forecasts, Reading, United Kingdom
}

(Manuscript received 28 February 2006, in final form 18 September 2006)

\begin{abstract}
In this paper, a version of the European Centre for Medium-Range Weather Forecasts (ECMWF) operational model is used to (i) diagnose the diabatic heating associated with the winter North Atlantic Oscillation (NAO) and (ii) assess the role of this heating in the dynamics of the NAO in the model. Over the North Atlantic sector, the NAO-related diabatic heating is dominated above the planetary boundary layer by the latent heat release associated with precipitation, and within the boundary layer by vertical diffusion associated with sensible heat flux from the ocean. An association between La Niña-El Niño-type conditions in the tropical Pacific and the positive/negative NAO is found in model runs using initial conditions and sea surface temperature (SST) lower boundary conditions from the period 1982-2001, but not in a companion set of model runs for the period 1962-81. Model experiments are then described in which the NAO-related diabatic heating diagnosed from the 1982-2001 control run is applied as a constant forcing in the model temperature equation using both 1982-2001 and 1962-81 model setups. To assess the local feedback from the diabatic heating, the specified forcing is first restricted to the North Atlantic sector alone. In this case, the model response (in an ensemble mean sense) is suggestive of a weak negative feedback, but exhibits more baroclinic structure and has its centers of action shifted compared to those of the NAO. On the other hand, forcing with only the tropical Pacific part of the diabatic heating leads to a robust model response in both the 1982-2001 and 1962-81 model setups. The model response projects on to the NAO with the same sign as that used to diagnose the forcing, arguing that the link between the tropical Pacific and the NAO is real in the 1982-2001 control run. The missing link in the corresponding run for 1962-81 is a result of a change in the tropical forcing between the two periods, and not the extratropical flow regime.
\end{abstract}

\section{Introduction}

As pointed out by Hoskins and Valdes (1990), a common observation in the atmosphere is that successive storms often follow the same track. Indeed, in the Northern Hemisphere winter, there are well-defined storm tracks that originate near the western boundary of the North Atlantic and North Pacific Oceans and extend eastward across the ocean interior. This appears to contradict the notion that storms release available potential energy, reducing the local baroclinicity, and requiring the baroclinicity to be reestablished before further storms can track in the same location. By looking at the dynamical response of a linear, stationary

Corresponding author address: Dr. Thomas Jung, ECMWF, Shinfield Park, Reading RG2 9AX, United Kingdom.

E-mail: thomas.jung@ecmwf.int wave model to specified forcings computed from observations, Hoskins and Valdes concluded that the release of latent heat within the storm track provides a diabatic forcing for the atmosphere that feeds back to maintain the baroclinicity of the storm track. In this sense, the storm tracks are described as being "self-sustaining." In particular, the baroclinic zone on which the storm track depends is maintained by the dynamical response of the atmosphere to the diabatic heating that results from the storm track itself.

Hoskins and Valdes' work raises a question as to whether the same mechanism operates to self-maintain the modes of low-frequency variability within the atmospheric circulation that are related to shifts in the positions of the storm tracks. Over the Euro-Atlantic sector, the most important pattern of low-frequency variability is the North Atlantic Oscillation (NAO). The NAO accounts for as much as $40 \%$ of the variance

DOI: $10.1175 / J C L I 4125.1$ 
in winter mean sea level pressure variability in that sector [see Greatbatch (2000) and Hurrell et al. (2003) for reviews of the NAO]. Winters of positive or negative NAO index are associated with displacements in the storm track over the North Atlantic (see, e.g., Rogers 1990). During negative NAO winters, the storm track is more zonally orientated near $40^{\circ} \mathrm{N}$, whereas in positive NAO winters, the storm track has a more southwest-northeast orientation. Exactly what atmospheric processes govern the magnitude and spatial structure of the NAO is still under discussion. However, from numerous previous studies (e.g., Robinson 1991; Branstator 1992; Hurrell 1995a; Feldstein and Lee 1998; DeWeaver and Nigam 2000) it is clear that "dry" eddy-mean flow interactions are crucial for the existence of the NAO [see Thompson et al. (2003) for a more comprehensive review of the existing literature]. In this paper, we use a version of the European Centre for Medium-Range Weather Forecasts (ECMWF) operational model to assess the role of diabatic forcing in the dynamics of the NAO. In particular, we are interested to know how the model responds to the largescale diabatic heating associated with the positive and negative phases of the NAO and, in particular, whether the NAO-related diabatic forcing over the North Atlantic region acts (in an ensemble mean sense) as a positive or a negative feedback on the NAO itself.

Evidence that the diabatic forcing acts as a positive feedback on the NAO has been put forward by Peterson et al. (2002) (see also Greatbatch et al. 2003). These authors showed that a simple, dynamical model of the atmosphere has skill at reproducing the past history of the winter NAO index in the ensemble mean when driven by empirical forcing computed from observations, and attributed this skill to a positive feedback from the release of latent heat in the storm track (but see the discussion on this model in section 4). Ting and Lau (1993), on the other hand, present evidence that the diabatic heating associated with the NAO plays a rather minor role (see also DeWeaver and Nigam 2000), but acts as a weak damping on the NAO in the upper troposphere. Evans and Black (2003) also find evidence that forcing associated with diabatic heating plays a role in both opposing the initial growth of weather regimes over the North Atlantic, and in assisting in their decay, again suggestive of a negative feedback. There is also evidence from models (e.g., Merkel and Latif 2002; Mathieu et al. 2004; Pohlmann and Latif 2005) and observations (e.g., Fraedrich and Müller 1992) that the NAO is influenced by diabatic forcing from the Tropics, an issue that remains controversial and which we explore further in this paper.

Aside from the intrinsic interest as to whether the
NAO-related diabatic heating of the atmosphere acts as a positive or negative feedback on the NAO, it is important to understand the role of diabatic processes in the dynamics of the NAO in order to clarify how the ocean, and in particular SST anomalies, influence the NAO (see, e.g., Czaja et al. 2003). The issue of how SST anomalies influence the NAO is, in turn, an essential aspect of understanding the degree to which the NAO is predictable on seasonal and decadal time scales (e.g., Rodwell 2003). Rodwell et al. (1999) showed that an AGCM driven by the observed time series of sea surface temperature (SST) and sea ice at its lower boundary can reproduce, in the ensemble mean, the past history of the observed NAO index, at least on time scales longer than about $6 \mathrm{yr}$. Other models also show this capability (e.g., Mehta et al. 2000; Latif et al. 2000). Rodwell et al. also showed that their model [the Hadley Centre Atmospheric Model 2 (AM2)] exhibits an NAO response to the SST pattern forced by the NAO over the North Atlantic Ocean consistent with a positive feedback from the NAO-driven SST anomalies. The influence of SST anomalies on the NAO is ultimately attributable to diabatic forcing of the atmosphere induced by the SST anomalies. In the Tropics, simple linear models have proved valuable tools for understanding the dynamical response of the atmosphere to diabatic heating sources (e.g., Gill 1980). In the extratropics, the problem is much more complex, involving nonlinear interaction and feedback between the diabatic forcing and the transient eddy field, that is, the storm track (Kushnir et al. 2002; Li and Conil 2003).

Following discussion of the model and the experimental setup in section 2, we begin in section 3 by describing the heat budget of the atmosphere associated with the NAO in the model. We then go on to describe the result of applying the diagnosed diabatic heating associated with the NAO as a forcing to the model, in order to ascertain the nature of the local feedback between the diabatic heating released in the storm track and the NAO as well as remote effects associated with diabatic forcing in the Tropics. The results are summarized in section 4 , where we also discuss some of the implications of our results.

\section{Methods}

The model used in this study is one of the latest versions of the ECMWF model (cycle 28rl) and was used operationally from 9 March to 27 September 2004. In this study a horizontal resolution of $T_{L} 95$ (linear Gaussian grid $\approx 1.875^{\circ}$ ) is used and 60 levels in the vertical are employed. About half of the levels are located above the tropopause. The highest model level is 
located at about $0.1 \mathrm{hPa}$. Some aspects of the model performance at this resolution are discussed in Jung and Tompkins (2003) and Jung (2005).

The model was first integrated for 6 months for each of the years from 1982 to 2001. Observed SST fields taken from the 40-yr ECMWF Re-Analysis (ERA-40; Uppala et al. 2005) were used at the lower boundary, and the model was started on 1 October of each year. We call this set of model runs the "control" integration. Additional model runs are also conducted (see section 4) in which diabatic forcing associated with the NAO, and diagnosed from the control run, is added as an extra, time-independent forcing to the model temperature equation, and the integration procedure repeated (i.e., twenty 6-month integrations for each year from 1982 to 2001). Only the months from December through March are used for the subsequent diagnosis. The fact that the first two months of the integrations have been discarded ensures that the focus is on the winter season and that the model has reached its own climatology (see Jung 2005). Subsequent results are based on monthly mean fields (a total of 80 fields for each 20 -yr period).

To effectively determine the robustness of our results all forced experiments for the period 1982-2001 (with the forcing taken from the control experiment over the period 1982-2001) were repeated using initial conditions and SST at the lower boundary from the independent 20-yr period $1962-81$. In this way it is possible to formulate hypotheses from the 1982-2001 period and to test them using the independent dataset from the period 1962-81.

The focus of this study is the diabatic forcing for the local temperature tendency in the model, in particular, that part of the forcing associated with the NAO. The diabatic processes simulated by the ECMWF model encompass radiative heating, vertical diffusion, gravity wave drag, as well as convective and large-scale precipitation. (Gravity wave drag plays no role in what follows, and will not be discussed further.) In the following, we shall refer to the total heating from precipitation, rather than the convective and large-scale contributions separately. It should be noted that precipitation heating refers to the latent heat release associated with condensation, and so can be expected to play a role in the storm track, and also in the Tropics where there is deep convection. Likewise, in the planetary boundary layer, vertical diffusion includes the heating of the atmosphere due to the sensible heat flux from the ocean. The adiabatic forcing for the local temperature tendency accounts for horizontal and vertical advection as well as adiabatic effects due to vertical motion. We shall find that on the time scales considered here, the total diabatic and total adiabatic temperature forcings show a large cancellation, implying a negligible role for heat storage in the atmosphere, as one would expect.

The variability associated with the NAO (including the diabatic forcing associated with the NAO), is identified by means of a composite analysis. To characterize temporal variations of the NAO, we use a monthly NAO index defined, following Walker (1924) and Rogers (1984), as the difference between the normalized monthly mean sea level pressure (SLP) time series from the grid points closest to the Azores and Iceland. We then composited monthly means of model variables whenever the model monthly NAO index is greater than one standard deviation positive, or less than one standard deviation negative.

\section{Results}

\section{a. The North Atlantic Oscillation}

To verify the character of the NAO in the model, we first produced composites from the control run of monthly anomalies of 500-hPa height (Z500) and 1000$\mathrm{hPa}$ height (Z1000) for the winter months (DecemberMarch) for both the positive and negative NAO index (as discussed above). The results (Fig. 1) show the characteristic tendency for 500- and 1000-hPa height to both be lower (higher) than normal near Iceland in high (low) index years, with correspondingly higher (lower) than normal values near the Azores. Both the magnitude and pattern of the high and low index composites compare well with observed estimates (e.g., Wallace and Gutzler 1981; Hurrell 1995b). Interestingly, the positive and negative composites are not the mirror image of each other (see also Cassou et al. 2004), suggesting there may be some difference in the dynamics of the different phases of the NAO in the model (see also Peterson et al. 2003). Figures 1e,f show high and low index composites based on monthly mean anomalies in the standard deviation of day-to-day changes in 500-hPa heights [see Jung (2005) for details about the characteristics of this high-pass filter], indicating the displacement in the storm track between high and low index months. Again we see the characteristic tendency for a strengthened (weakened) storm track from Newfoundland, Canada, to the Norwegian Sea in high (low) index months with bands of weakened (increased) storm activity to the north and south, much as in the observations.

\section{b. Heat budget over the North Atlantic region}

We now turn to the forcing for the local temperature tendency in the ECMWF model diagnosed from the 
(a) Z500 Anomaly: High NAO (Dec-Mar 1980-2001)

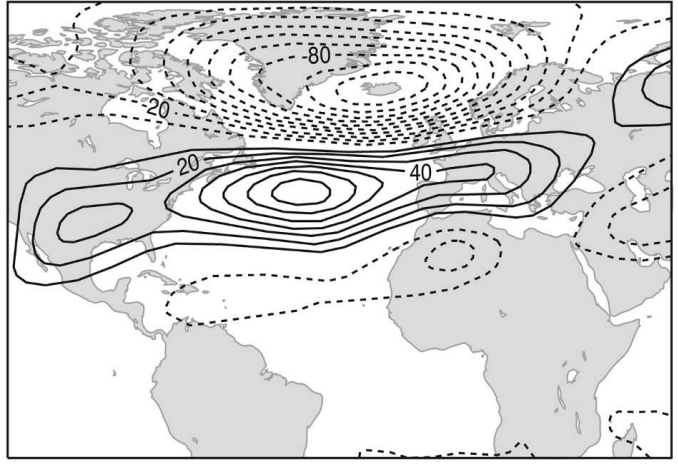

(c) Z1000 Anomaly: High NAO (Dec-Mar 1980-2001)

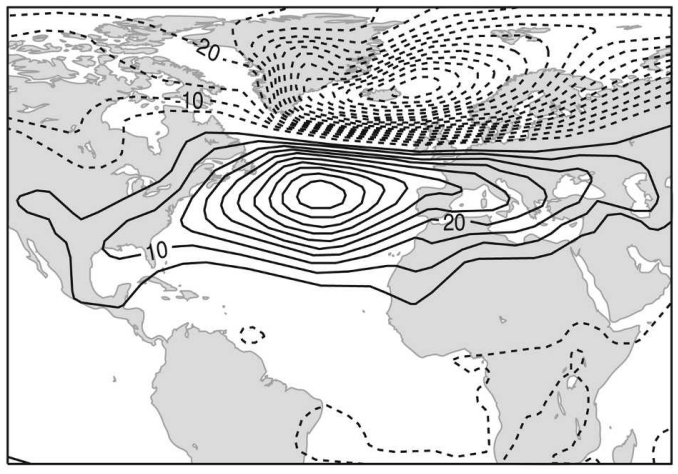

(e) Synoptic Z500 Activity: High NAO (Dec-Mar 1980-2001)

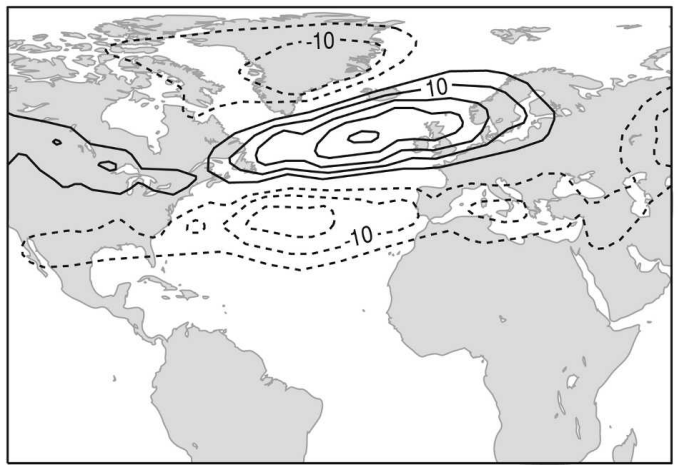

(b) Z500 Anomaly: Low NAO (Dec-Mar 1980-2001)

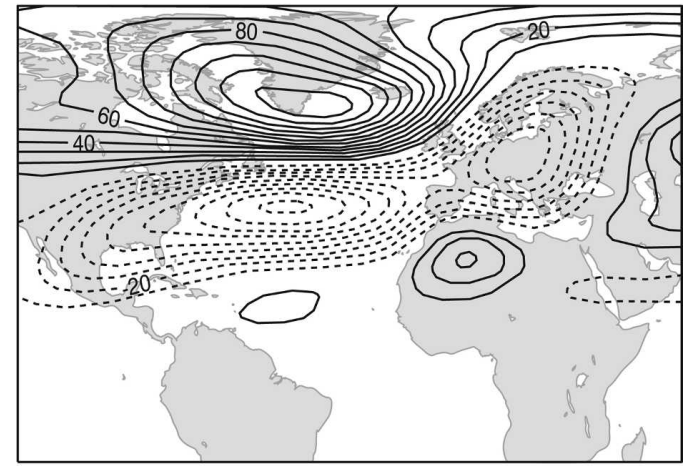

(d) Z1000 Anomaly: Low NAO (Dec-Mar 1980-2001)

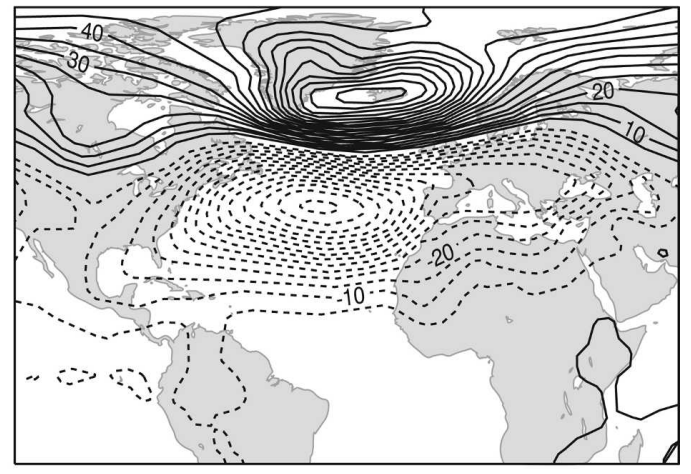

(f) Synoptic Z500 Activity: Low NAO (Dec-Mar 1980-2001)

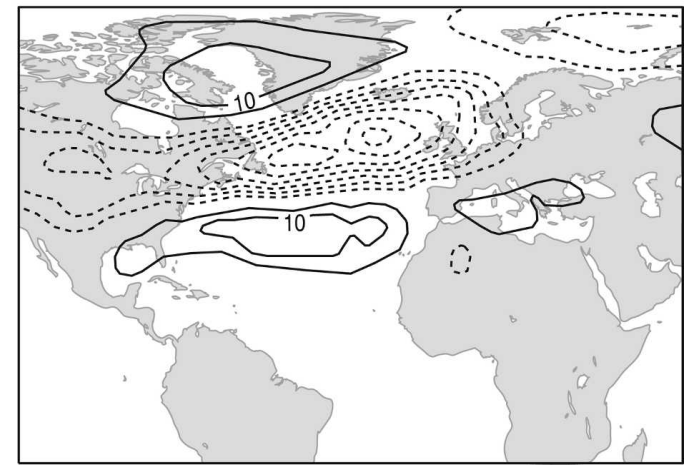

FIG. 1. Monthly mean anomalies associated with the high and low phase of the NAO during winter months of the period 1982-2001 for the ECMWF model: (a),(b) 500-hPa geopotential height [contour interval (CI) is $10 \mathrm{~m}$ ), (c), (d) 1000-hPa geopotential height (CI is $5 \mathrm{~m}$ ), and (e),(f) synoptic Z500 activity (CI is $5 \mathrm{~m} \mathrm{day}^{-1}$ ). High NAO conditions are represented in (a), (c), and (e) and low NAO conditions are represented in (b), (d), and (f). A threshold of $\mp 1$ std dev of the monthly NAO index has been used for compositing. Shown are differences between the composites and long-term means. Synoptic Z500 activity is defined as the std dev of day-to-day Z500 changes.

control run. Figure 2 shows this forcing, zonally averaged over the North Atlantic region $\left(100^{\circ} \mathrm{W}-20^{\circ} \mathrm{E}\right)$. The winter climatological forcing is shown using contours, and the difference between high and low NAO index composites is shown using shading. For both the climatology and the high minus low index composites, we see that there is a cancellation between the total diabatic and adiabatic temperature forcing, indicating, as noted earlier, that there is no significant role for heat storage in the atmosphere on the time scales (monthly mean and longer) studied here. Not surprisingly, the radiative forcing has a role to play in the climatological forcing balance, the net effect being a radiative heat loss to space everywhere outside the near-surface zone. 
(a) Total Diabatic T Tendency

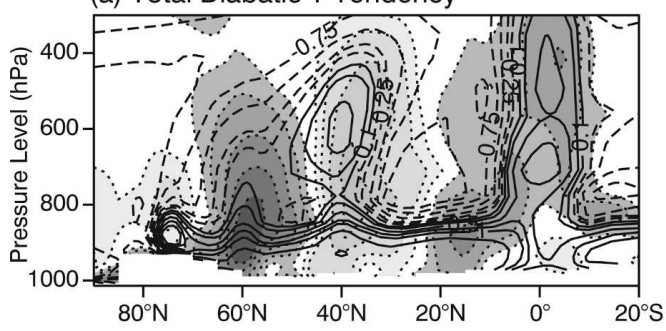

(c) Radiative Heating

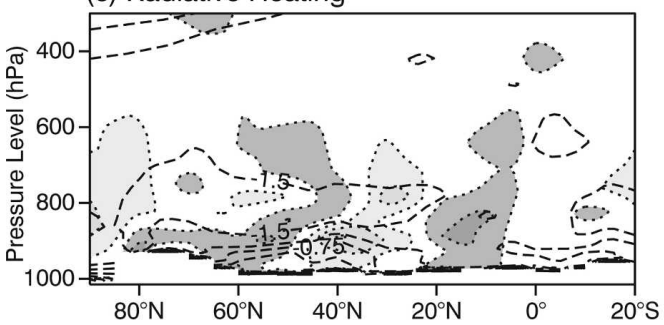

(e) Precipitation

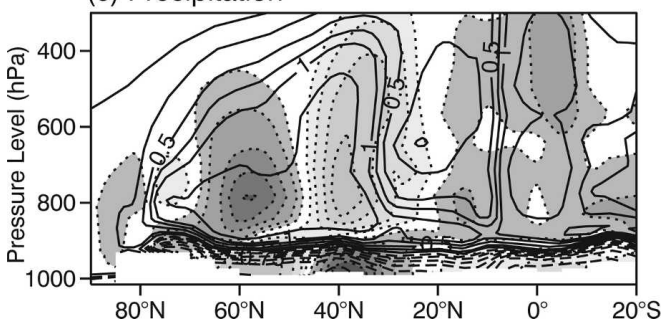

(b) Adiabatic T Tendency

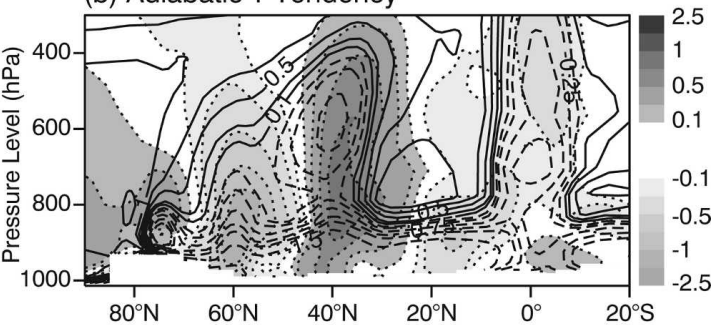

(d) Vertical Diffusion

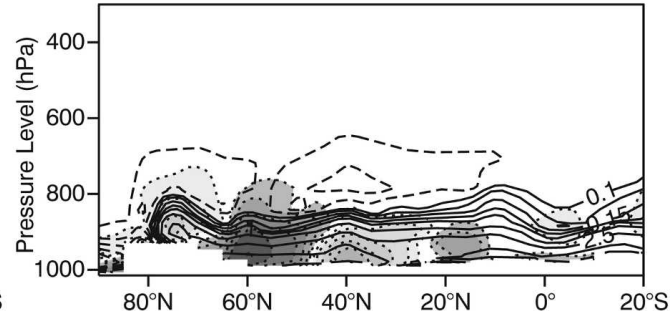

FIG. 2. Zonal average of the wintertime [DecemberMarch (DJFM)] temperature forcing $\left(\mathrm{K} \mathrm{day}^{-1}\right)$ over the North Atlantic region $\left(100^{\circ} \mathrm{W}-20^{\circ} \mathrm{E}\right)$ for the ECMWF model (1982-2001): (a) total diabatic forcing, (b) adiabatic forcing, (c) radiative forcing, (d) vertical diffusion, and (e) total precipitation. Differences between high and low NAO composites are gray shaded. The climatology forcing of the model-i.e., the average of the forcing over the winter season and all years-is also shown [contour lines are for $\pm 0.1, \pm 0.25, \pm 0.5, \pm 0.75, \pm 1.0, \pm 1.5, \pm 2.5, \pm 4 \mathrm{~K}$ day $^{-1}$; positive (negative) contours are solid (dashed)].

ocean counters opposite-signed anomalies associated with precipitation that are, themselves, of opposite sign to the precipitation anomalies above the boundary layer. The change in sign of the anomalous precipitation heating at the top of the boundary layer is because of cooling due to evaporation of precipitation within the boundary layer itself. The above results are consistent with column-integrated NAO-related anomalous heating rates described by De Weaver and Nigam (2000).

The above conclusions are further clarified by the horizontal plan views shown in Figs. 3 and 4 at two different levels, roughly 960 and $540 \mathrm{hPa}$, respectively. Again, at both levels, we see the balance between the net diabatic and adiabatic temperature forcing. The role of the vertical diffusion (in particular, sensible heat flux from the ocean) is clearly evident in the boundary layer (Fig. 3d), where, as before, the sign of the total diabatic heating is determined by the vertical diffusion, but plays virtually no role in the free atmosphere (Fig. 4d). At $540 \mathrm{hPa}$, on the other hand, the difference composite is dominated by the contribution from the precipitation, with the radiative forcing, as noted previously, having only a minor role to play. An interesting feature in Figs. 3 and 4 is that heating anomalies asso- 
(a) Diabatic T Forcing (High-low NAO, lev $=54$ )

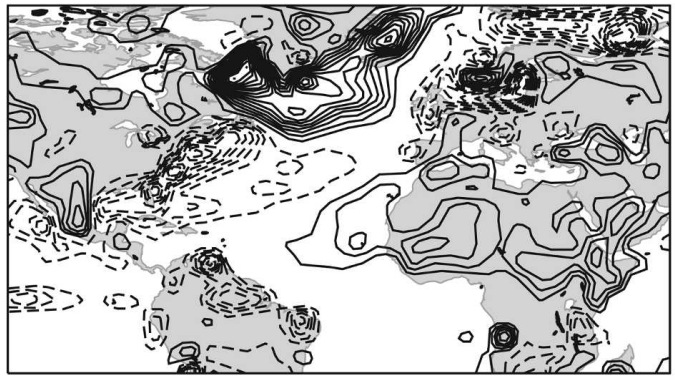

(c) Radiative Heating (High-low NAO, lev=54)

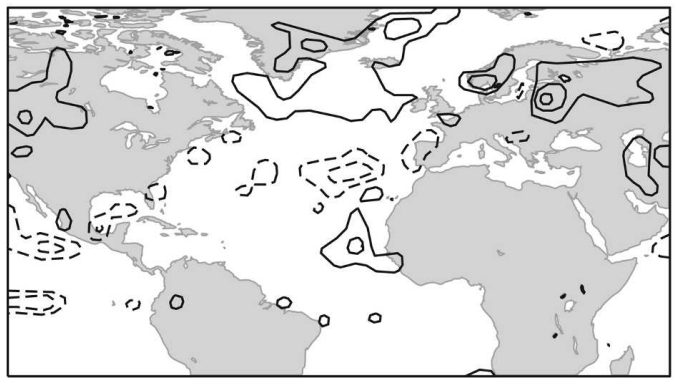

(e) Total Precipitation (High-low NAO, lev $=54$ )

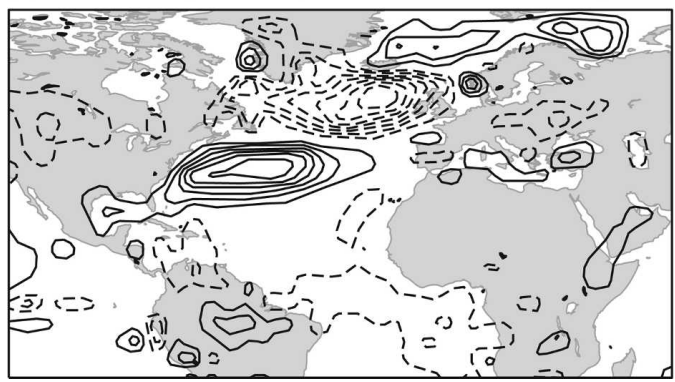

ciated with precipitation are often found downstream of heating anomalies of the same sign due to vertical diffusion (predominantly heat flux from the ocean). A good example is the region of heat gain over the Labrador Sea in the high-minus-low index composite shown in Fig. 3, and the corresponding region of precipitation heating in a band farther east, north of the British Isles, in Fig. 4. As noted earlier, the enhanced (reduced) sensible heat loss over the Labrador Sea associated with the positive (negative) NAO is also associated with enhanced (reduced) evaporation, and hence anomalies in moisture input to the atmosphere that feed the corresponding precipitation heating anomalies.

\section{c. The local diabatic feedback}

In the perturbed experiments, the sensitivity of the atmospheric circulation to the NAO-related diabatic (b) Adiabatic T Forcing (High-low NAO, lev=54)

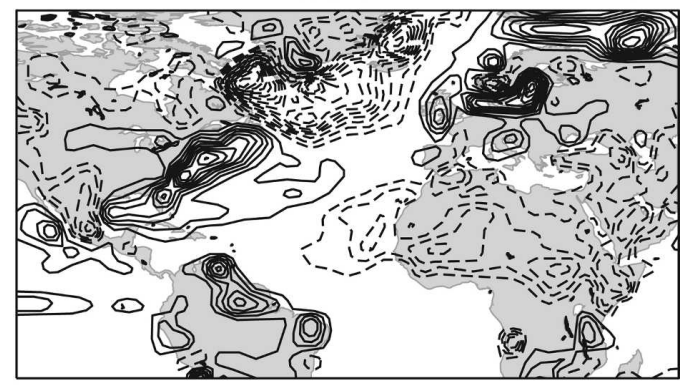

(d) Vertical Diffusion (High-low NAO, lev=54)

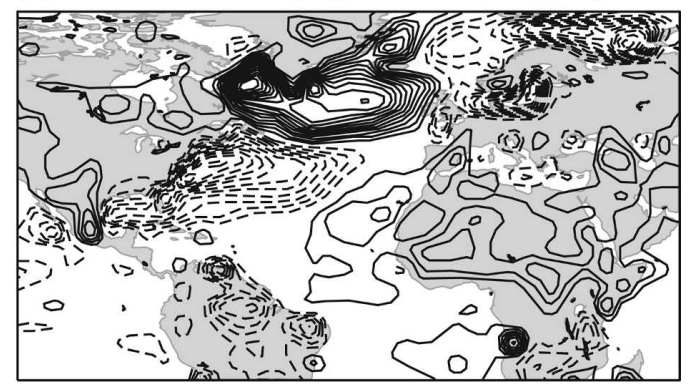

FIG. 3. Mean difference of the temperature forcing at model level 54 (about $960 \mathrm{hPa}$ ) between high and low NAO composites (contour interval is $0.4 \mathrm{~K} \mathrm{day}^{-1}$ ) for the ECMWF model: (a) total diabatic forcing, (b) adiabatic forcing, (c) radiative forcing, (d) vertical diffusion, and (e) total precipitation. The compositing technique is the same as that used to produce Fig. 1. Positive (negative) contours are solid (dashed). Results are based on winters (December-March) of the period 1982-2001.

forcing is studied by applying the diabatic heating diagnosed from the control run (1982-2001) as a timeindependent forcing to the model temperature equation during the full cycle of integrations with the model (i.e., throughout each of the 6-month integrations for each year of the periods 1982-2001 and 1962-81, respectively). In particular, the model equations become

$$
\frac{d \mathbf{x}_{t}}{d t}=\mathbf{G}\left(\mathbf{x}_{t}\right)+\mathbf{F}_{\mathrm{NAO}}
$$

where $\mathbf{x}_{t}$ describes the time-dependent atmospheric state vector, $\mathbf{G}$ symbolizes the dynamical and physical part of the ECMWF model, and $\mathbf{F}_{\mathrm{NAO}}$ is the timeindependent NAO-related forcing that is nonzero for the temperature equation only. For the positive (negative) NAO cases shown below, the forcing $\mathbf{F}_{\text {NAO }}$ is the positive (negative) NAO composite diagnosed from the control run (1982-2001). 
(a) Diabatic T Forcing (High-low NAO, lev=40)

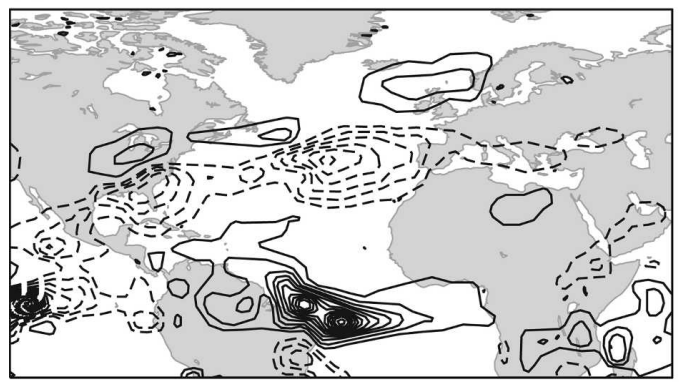

(c) Radiative Heating (High-low NAO, lev=40)

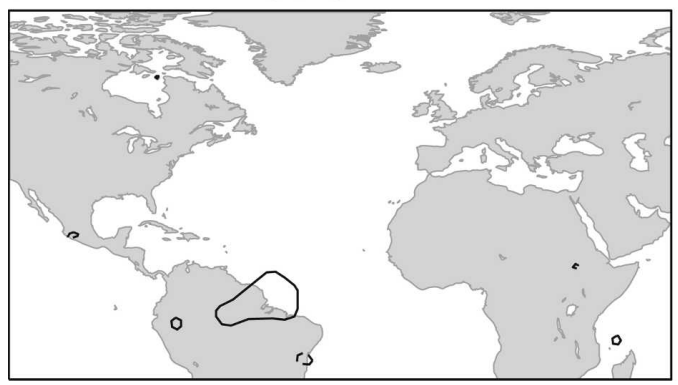

(e) Total Precipitation (High-low NAO, lev $=40$ )

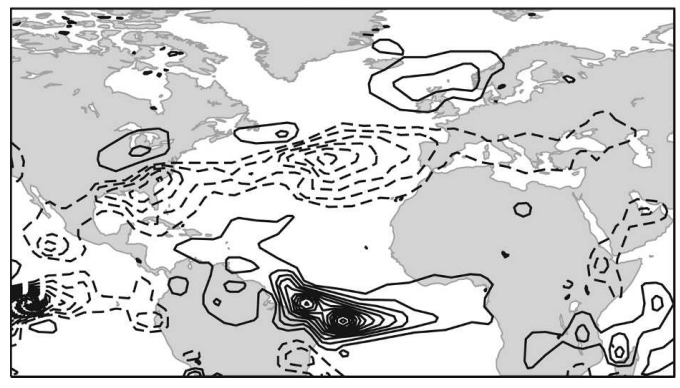

We begin by assessing the local feedback from the NAO-related diabatic heating (mostly latent heat release in the storm track and sensible heat exchange with the ocean). Figure 5 shows the mean model response when the total diabatic forcing is restricted to the North Atlantic region only. The model response is very similar in both sets of experiments (1962-1981 and 19822001), indicating its robustness. At $500 \mathrm{hPa}$, the model shows an NAO-like response that, furthermore, is of the opposite sign to that associated with the forcing in both the positive and negative NAO cases, suggestive of a negative feedback [see also the probability density functions (pdfs) in Figs. 6a,d]. The centers of action are nevertheless shifted (mostly eastward) from those associated with the NAO (see Fig. 1) and there is no significant response at $1000 \mathrm{hPa}$ (not shown). It follows that the model response is actually quite baroclinic (see also Ting and Lau 1993), in contrast to the equivalent barotropic structure of the NAO itself (see Figs. 1a-d). In summary, we can say there is evidence of a weak, (b) Adiabatic T Forcing (High-low NAO, lev=40)

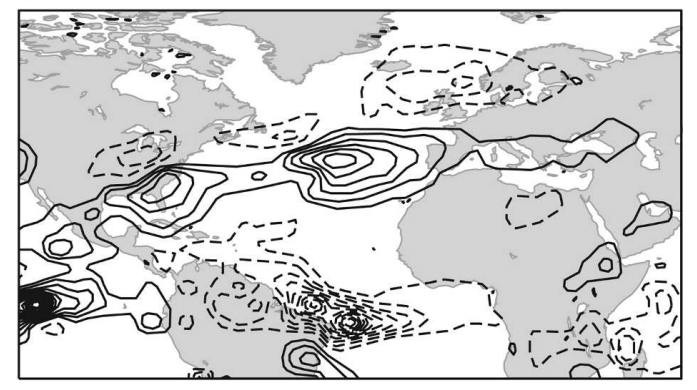

(d) Vertical Diffusion (High-low NAO, lev $=40$ )

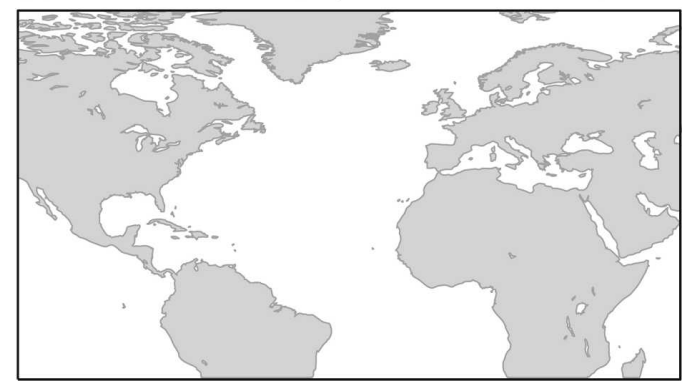

Fig. 4. Same as Fig. 3, except for model level 40 (about $540 \mathrm{hPa}$ ).

negative feedback from the diabatic heating over the North Atlantic region on the NAO, although the feedback has baroclinic structure, rather the equivalent barotropic structure associated with the NAO.

\section{d. Forcing from the tropical Pacific}

It is possible that diabatic forcing outside the North Atlantic region may impact the NAO. Figure 7 shows the diabatic temperature forcing vertically integrated from 850 to $200 \mathrm{hPa}$ for the control run (Fig. 7d), and the anomalous heating that goes along with the negative (Fig. 7e) and positive (Fig. 7f) NAO in the control run. By focusing on the free troposphere the diabatic forcing is dominated by the release of latent heat (i.e., precipitation). The anomalous heating in the negative NAO case is clearly indicative of El Niño (warm) conditions in the central tropical Pacific (cf. DeWeaver and Nigam 2000, their Fig. 7). For the positive NAO case, on the other, the relation to the ENSO phenomenon is less clear; most of the anomalous cooling associated the 
(a) Z500 Difference:

High NAO-Control (Dec-Mar 1962-1981)

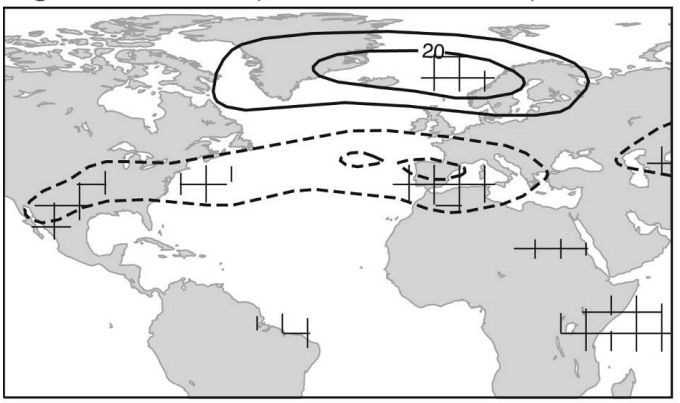

(c) Z500 Difference:

High NAO-Control (Dec-Mar 1982-2001)

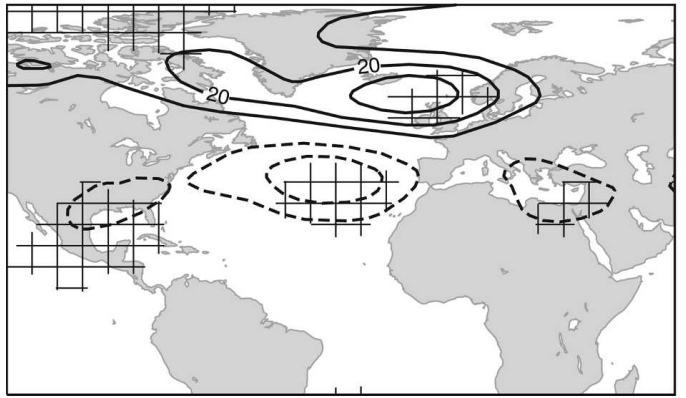

(b) Z500 Difference:

Low NAO-Control (Dec-Mar 1962-1981)

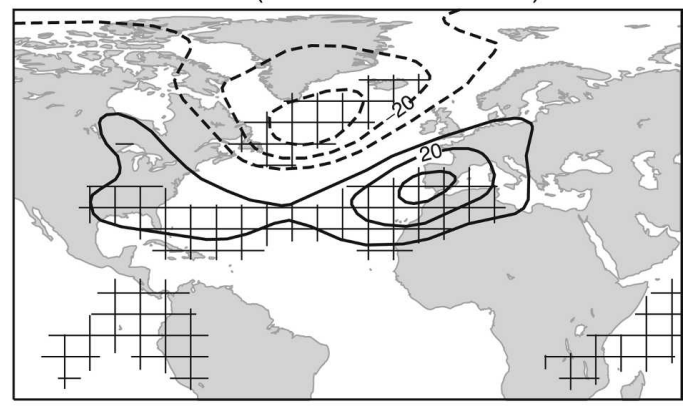

(d) Z500 Difference:

Low NAO-Control (Dec-Mar 1982-2001)

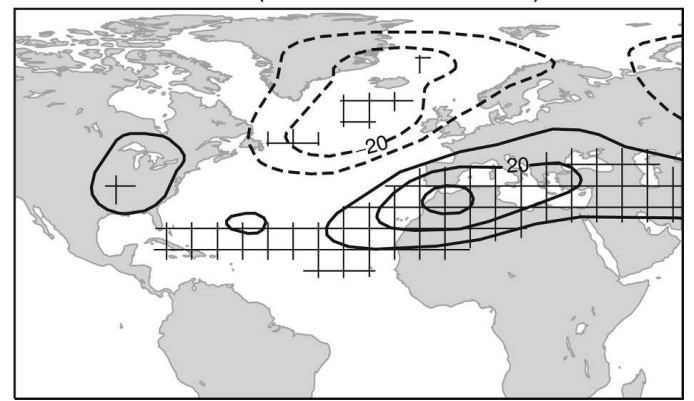

FIG. 5. Difference of the mean Z500 fields between an experiment with additional, NAO-related diabatic forcing specified in the North Atlantic region only (there is no additional forcing outside the area $20^{\circ}-70^{\circ} \mathrm{N}, 100^{\circ} \mathrm{W}-20^{\circ} \mathrm{E}$ ) associated with the (a), (c) positive and (b), (d) negative phase of the NAO, and an unperturbed integration with no additional forcing. Results are shown for the period 1962-81 in (a) and (b) and 1982-2001 in (c) and (d). Notice that the same forcing (obtained using model data from 1982 to 2001) has been applied for the two periods 1962-81 and 1982-2001. Statistically significant differences (at the 95\% confidence level) are hashed.

positive NAO is found just west of the date line, whereas the strongest anomalous cooling associated with La Niña is located just east of the date line (DeWeaver and Nigam 2002). Given that the focus of this study is on monthly mean anomalies one alternative way of interpreting the heating anomalies in the tropical Pacific is, for example, that they maybe partly influenced by the 30-60-day tropical oscillation, or Madden and Julian oscillation (MJO; Madden and Julian 1971). The emphasis on the western tropical Pacific may not be surprising, however. Li et al. (2006) have noted that an SST anomaly in the western tropical Pacific is better able to excite the Northern Annular Mode (closely related to the NAO) than an SST anomaly in the eastern tropical Pacific, and Kucharski et al. (2006) have shown that SST anomalies in the western tropical Pacific can also influence the NAO on interdecadal time scales.

To investigate the role of tropical forcing on the monthly mean NAO, two experiments have been carried out in which the diabatic forcing is restricted to the tropical Pacific $\left(20^{\circ} \mathrm{S}-20^{\circ} \mathrm{N}, 100^{\circ} \mathrm{W}-100^{\circ} \mathrm{E}\right)$, and is associated with each of the negative and positive NAO (see Figs. 7e,f). The model response for both the positive and negative NAO cases shows what looks like a wave train that originates over the tropical Pacific (Fig. 8), reminiscent of the Pacific-North America (PNA) pattern (see Wallace and Gutzler 1981). There are, however, important differences between the two wave trains. In particular, the wave train in the negative NAO case (associated with anomalous El Niño-type heating in the tropical Pacific) is much stronger, particularly in the North Pacific basin, and seems to originate farther to the east than the wave train associated with the positive NAO forcing (anomalous atmospheric cooling in the western tropical Pacific). These conclusions are confirmed by Fig. 9, which shows the difference in the mean 200-hPa divergent wind and Rossby wave source [following Eq. (3) in Sardeshmukh and Hoskins (1988)] between each of the negative and positive NAO-forced cases and the control run. These figures show a strong Rossby wave source associated with an anomalous outflow from the central tropical Pacific in the case of the negative NAO (Fig. 9b) (as one would expect in an El Niño situation), compared to an anomalous inflow that is shifted to the west in the positive 

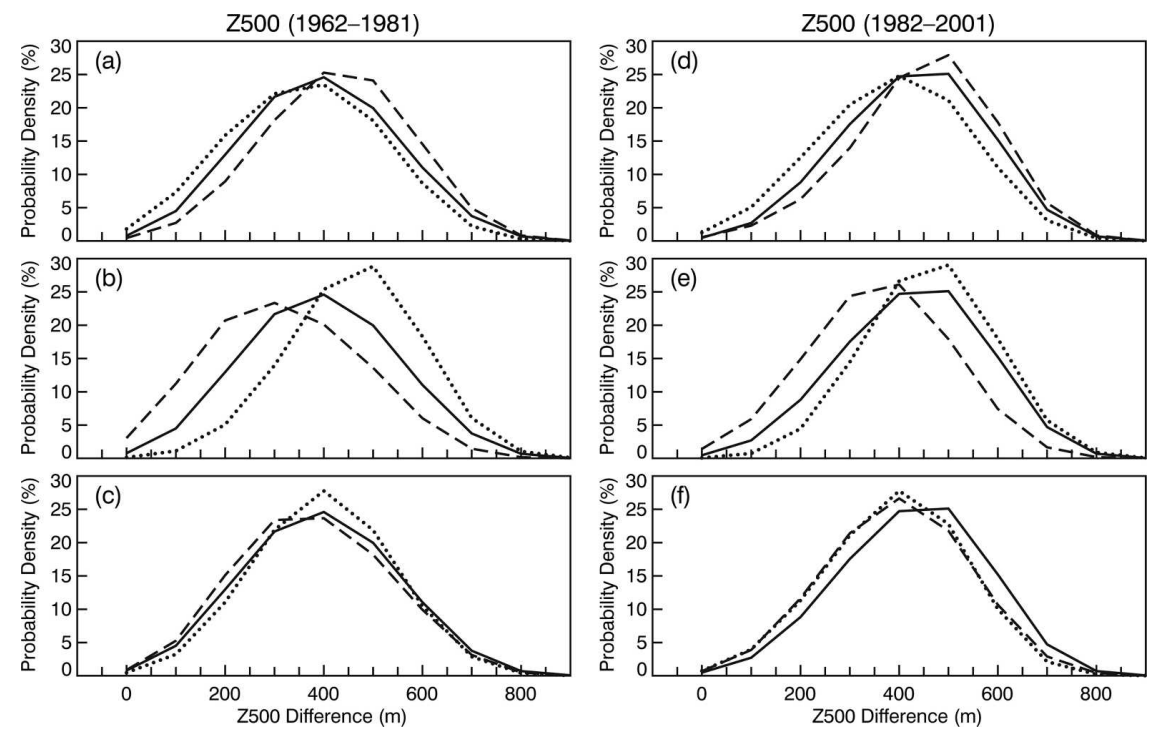

FIG. 6. Smoothed pdfs for the monthly mean Z500 difference between the Azores and Iceland for the periods (left) 1962-81 and (right) 1982-2001. The solid lines show the control run in all cases. The dotted (dashed) lines show the experiments for diabatic forcings associated with the positive (negative) NAO. Pdfs for (a), (d) North Atlantic, (b), (e) tropical Pacific, and (c), (f) global forcing. To describe the variations in the strength of the Azores high (Icelandic low), geopotential height fields were averaged over the area $35^{\circ}-45^{\circ} \mathrm{N}, 0^{\circ}-60^{\circ} \mathrm{W}$ $\left(60^{\circ}-70^{\circ} \mathrm{N}, 0^{\circ}-60^{\circ} \mathrm{W}\right)$. Smoothed pdfs were obtained by using a Gaussian kernel with a window width of $100 \mathrm{~m}$.

NAO case (Fig. 9c) [the negative NAO case (Fig. 9b) also indicates a Rossby wave source over the Gulf of Mexico]. In summary, the nonlinearity of the model response (both in terms of its magnitude and structure) in the North Pacific can readily be explained by the longitude and magnitude of the diabatic heating and hence the Rossby wave source.

A significant response to the tropical heating can also be found in the North Atlantic region, which is reminiscent of the canonical ENSO response (Fraedrich and Müller 1992), that is, anomalous warm (cold) conditions in the tropical Pacific is associated with the negative (positive) phase of the NAO (Figs. 6b,e and 8). The pdf of the NAO index (Figs. 6b,e) is clearly shifted toward negative values compared to the unperturbed integrations (solid lines) for the El Niño-type heating (dashed lines) in both independent sets of model runs (1982-2001 and 1962-81) indicating that the model response is robust and reproducible. For the case of the cooling in the tropical Pacific a noticable shift of the pdf is also apparent for the period 1962-81 (Fig. 6b). For the other period, 1982-2001, however, the pdf of the forced experiment is less clearly separated from that of the unperturbed integration (but with the suggestion that the positive phase of the NAO is more frequently occupied in the perturbed, compared to the unperturbed run) (Fig. 6e). At first glance this may suggest that the NAO response to La Niña-type conditions in the tropical Pacific is not significant. It is worth pointing out in this context, however, that the pdf of the NAO of the unperturbed integration is shifted toward positive values in the period 1982-2001 compared to 1962-81. Recall that this shift is consistent with the observed prevalence of the positive phase of the NAO during the last part of the twentieth century (Hurrell 1995b) and that observed SST anomalies were used as a lower boundary condition in the model integrations. Moreover, the pdfs of the NAO for the experiment with anomalous cooling in the tropical Pacific during the period 1982-2001 is very similar to that during 1962-81. This suggests that the ECMWF model indeed responds in a robust manner to the diabatic cooling in the tropical Pacific akin the canonical response described by Fraedrich and Müller (1992).

All sensitivity experiments with temperature forcing applied in the tropical Pacific were carried out with underlying, observed SST fields taken from the ERA40 reanalysis. Hence, the total forcing - that is, the imposed constant diabatic forcing and the observed anomalous forcing from the sea surface-may lead to excessive amounts of diabatic forcing during moderate and strong ENSO events (e.g., such as in 1997/98). To circumvent this problem we have also diagnosed the atmospheric response to the anomalous NAO-related 
(a) Climatological Mean Diabatic Temperature Forcing: (850-150 hPa DJFM 1962-1981)

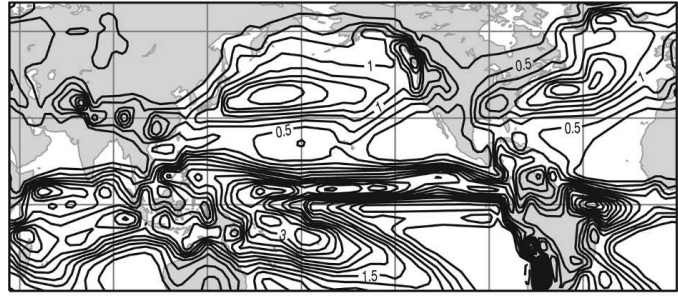

(b) Anomalous Monthly Mean Temperature Forcing: Low NAO (850-150 hPa DJFM 1962-1981)

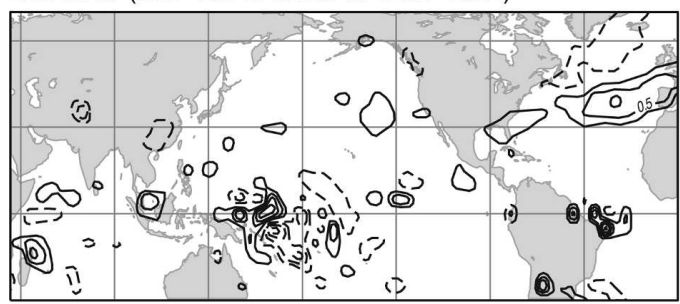

(c) Anomalous Monthly Mean Temperature Forcing: High NAO (850-150 hPa DJFM 1962-1981)

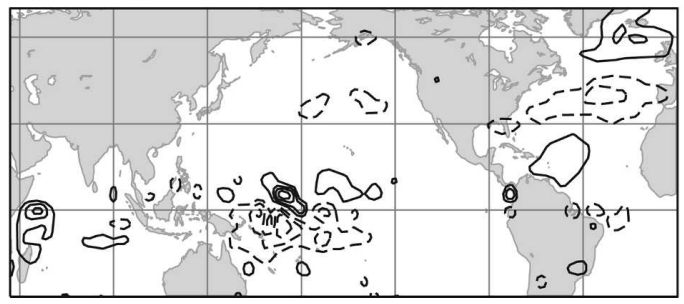

(d) Climatological Mean Diabatic Temperature Forcing: (850-150 hPa DJFM 1982-2001)

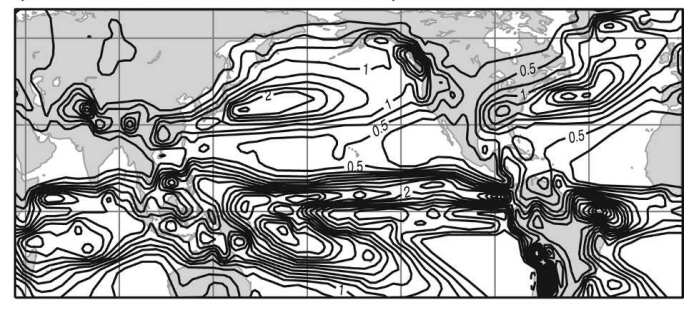

(e) Anomalous Monthly Mean Temperature Forcing: Low NAO (850-150 hPa DJFM 1982-2001)

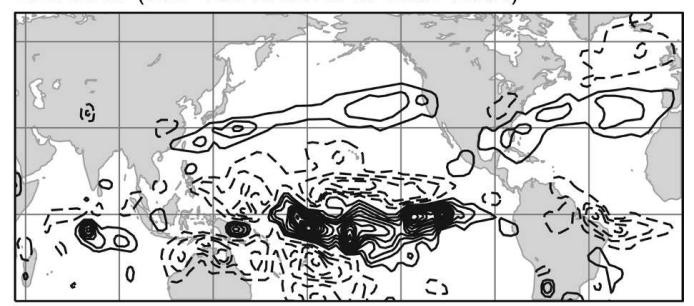

(f) Anomalous Monthly Mean Temperature Forcing: High NAO (850-150 hPa DJFM 1982-2001)

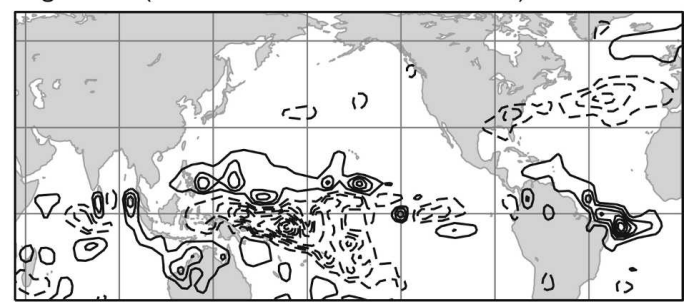

FIG. 7. Diabatic heating $\left(\mathrm{K} \mathrm{day}^{-1}\right)$ from the unforced integration vertically integrated from 850 to $200 \mathrm{hPa}$ for the period (a)-(c) 1962-81 and (d)-(f) 1982-2001. (a), (d) Climatological mean values. (b), (e) Differences between low NAO months and climatological mean values. (c), (f) Same as in (b), (e), but for high NAO months. The CI interval of $0.25 \mathrm{~K} \mathrm{day}^{-1}$ is used in all panels.

tropical forcing during non-ENSO years only. It turns out that the remote response for non-ENSO years only is comparable to that described above for all years (not shown).

One might argue that the link between the monthly $\mathrm{NAO}$ and the forcing in the tropical Pacific in the ECWMF model, which has been identified by means of a statistical technique (Fig. 7), may be spurious due to the shortness of the time series used (1982-2001). The notion that there is a causal link (the tropical Pacific forcing the NAO) in the ECMWF model during the period 1982-2001 is supported by the fact that a consistent response is found in two independent (in terms of the initial and boundary conditions) sensitivity experiments (Fig. 8). On the other hand, in turns out that a significant link between the NAO and warm and cool conditions the tropical Pacific is missing in the unperturbed integration for the period 1962-81. This is evident in Figs. 7b,c, from which it is clear that the diabatic heating in the tropical Pacific that goes along with the
NAO in the unperturbed experiment 1962-81 is very different from that in the control run (1982-2001; Figs. $7 \mathrm{e}, \mathrm{f})$, with no evidence of a relationship between the NAO and El Niño- or La Niña-type conditions in the tropical Pacific in the 1962-81 period. How can theseseemingly contradictory-results be explained? Since forcing the model with the tropical diabatic forcing diagnosed from the 1982-2001 unperturbed (control) run leads to the same basic response using both the 1962-81 and 1982-2001 model setups (Fig. 8), it follows that the failure to find the tropical link in the 1962-81 unperturbed run is not because of changes in the extratropical flow field between the two periods, but rather because of a change in the tropical forcing related to the underlying SST. Differences in the standard deviation of SST fields, used as lower boundary conditions in the model integrations, between the period 1982-2001 and 1962-81 are shown in Fig. 10a. It turns out that the magnitudes of ENSO-related SST anomalies seen by the model are substantially larger during the period 
(a) Z500 Difference:

High NAO-Control (Dec-Mar 1962-1981)

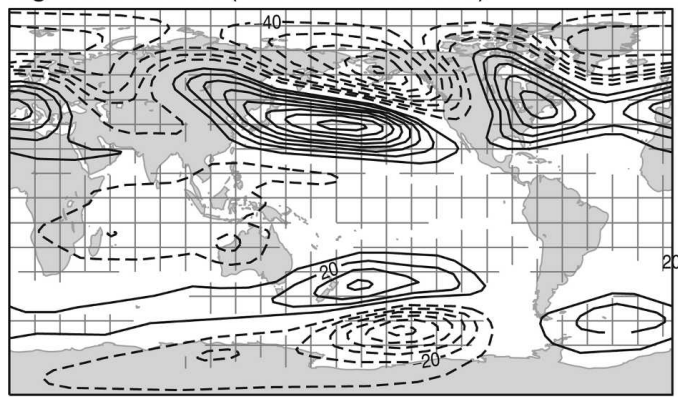

(c) Z500 Difference:

High NAO-Control (Dec-Mar 1982-2001)

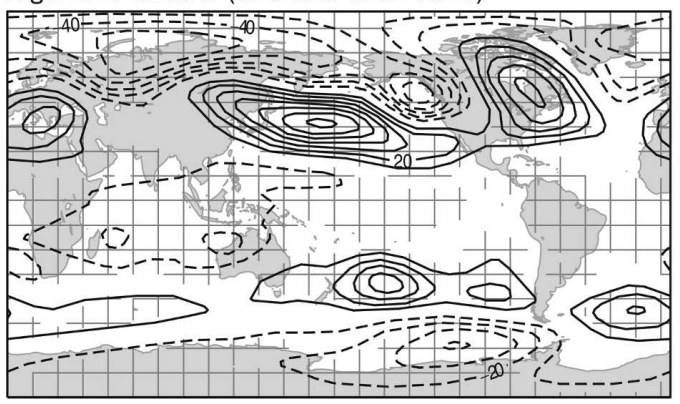

(b) Z500 Difference:

Low NAO-Control (Dec-Mar 1962-1981)

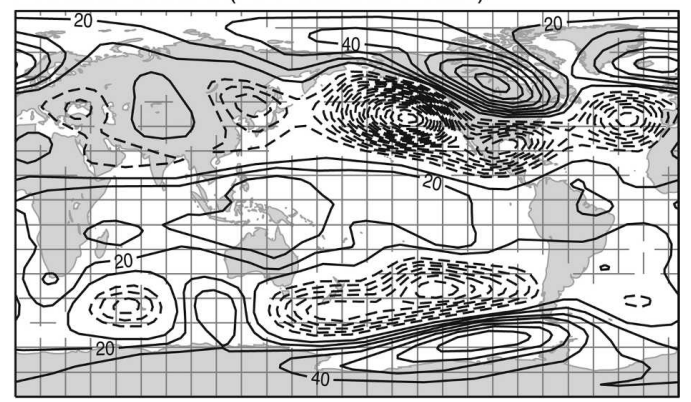

(d) Z500 Difference:

Low NAO-Control (Dec-Mar 1982-2001)

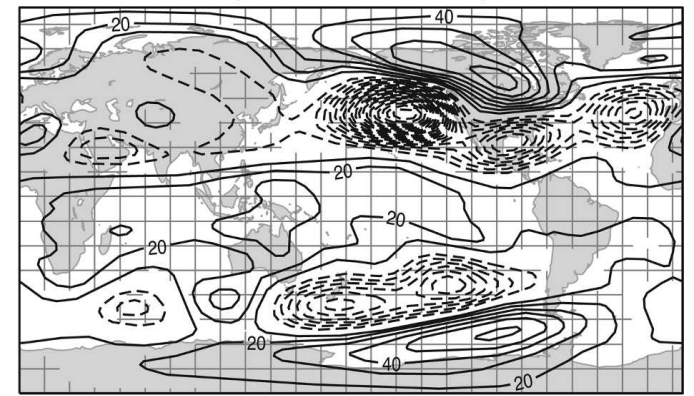

FIG. 8. Same as in Fig. 5, but for the NAO-related tropical Pacific heating (there is no additional forcing outside the tropical Pacific, $20^{\circ} \mathrm{S}-20^{\circ} \mathrm{N}$ and $100^{\circ} \mathrm{E}-100^{\circ} \mathrm{W}$ ).

1981-2001 compared to 1962-81. Therefore, the relatively small magnitude of ENSO-related SST anomalies during the period 1962-81 might explain why the link between the NAO and the tropical Pacific is missing in the unperturbed integration for this period. It is also possible that a change in the structure of the diabatic heating over the tropical Pacific associated with the shift to warmer, El Niño-like conditions after 1976 (see Trenberth et al. 2002) is a factor in explaining the difference between the 1962-81 and 1982-2001 model runs. For example, Branstator (1985) has noted that the extratropical response of a model to tropical forcing can be sensitive to small changes in the pattern of the tropical forcing (see also Greatbatch et al. 2004). Of particular interest is the increase in sea level pressure variability in the western tropical Pacific in 1982-2001 compared to 1962-1981 in both the observations and the model (Figs. 10b,c). We noted earlier that it is the western tropical Pacific region that appears to be the most effective at forcing the NAO (Fig. 7; Li et al. 2006; Kucharski et al. 2006). The increase in SLP variability in this region is likely related to both the increase in SST variability in the eastern tropical Pacific and the 1976/77 climate shift.

The SST fields used in this study are taken from the ERA-40 reanalysis (Uppala et al. 2005) and are based on a dataset from the Met Office Hadley Centre (Rayner et al. 2003) for the period 1956-81; thereafter weekly National Centers for Environmental Prediction (NCEP) two-dimensional variational data assimilation (2DVAR) data (Reynolds et al. 2002) were used (see Fiorino 2004 for details). It is possible that the additional use of satellite-based SST retrievals in ERA-40 from 1982 onward led to a spurious increase in ENSOrelated SST variability. This notion is supported by the study of Torrence and Compo (1998), who found similar levels of ENSO-related SST variability in the 2-8-yr band from the 1960s onward (see their Fig. 8). On the other hand, visual inspection of the "cold tongue" SST time series by Quadrelli and Wallace (2002) shows increased levels of ENSO-related SST variability since the early 1980s. Their index is based on data from the Comprehensive Ocean Atmosphere Data Set (COADS) and therefore free of inhomogeneities arising from the availability of satellite data in the late 1970s. One might argue that for the increase of interannual SST variability in ERA-40 to be realistic, ENSO-related SLP variability should increase accordingly. Differences of SLP variability in ERA-40 between the period 1982-2001 and 1962-81 are shown in Fig. 10b. The increase in SLP variability is, if anything, modest in the centers of action of the Southern Oscil- 
(a) Control Integration: 200hPa divergent wind and Rossby wave source (DJFM 1982-2001)

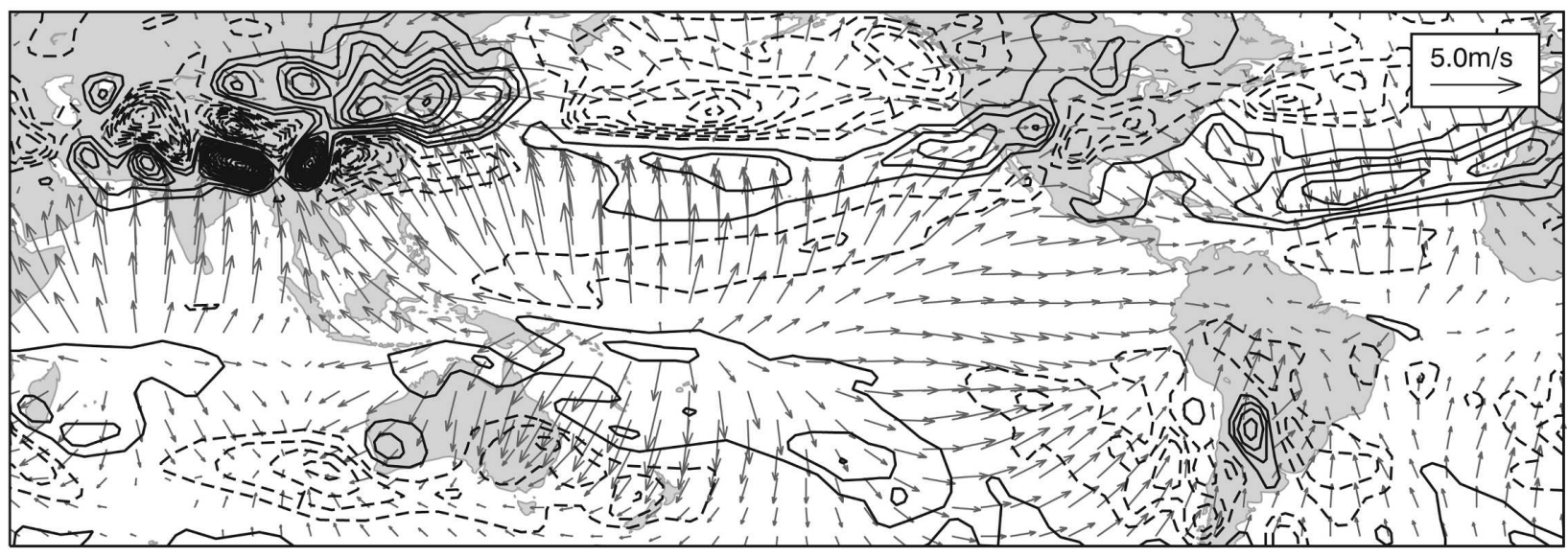

(b) Low NAO-CNTL: 200hPa divergent wind and Rossby wave source (DJFM 1982-2001)

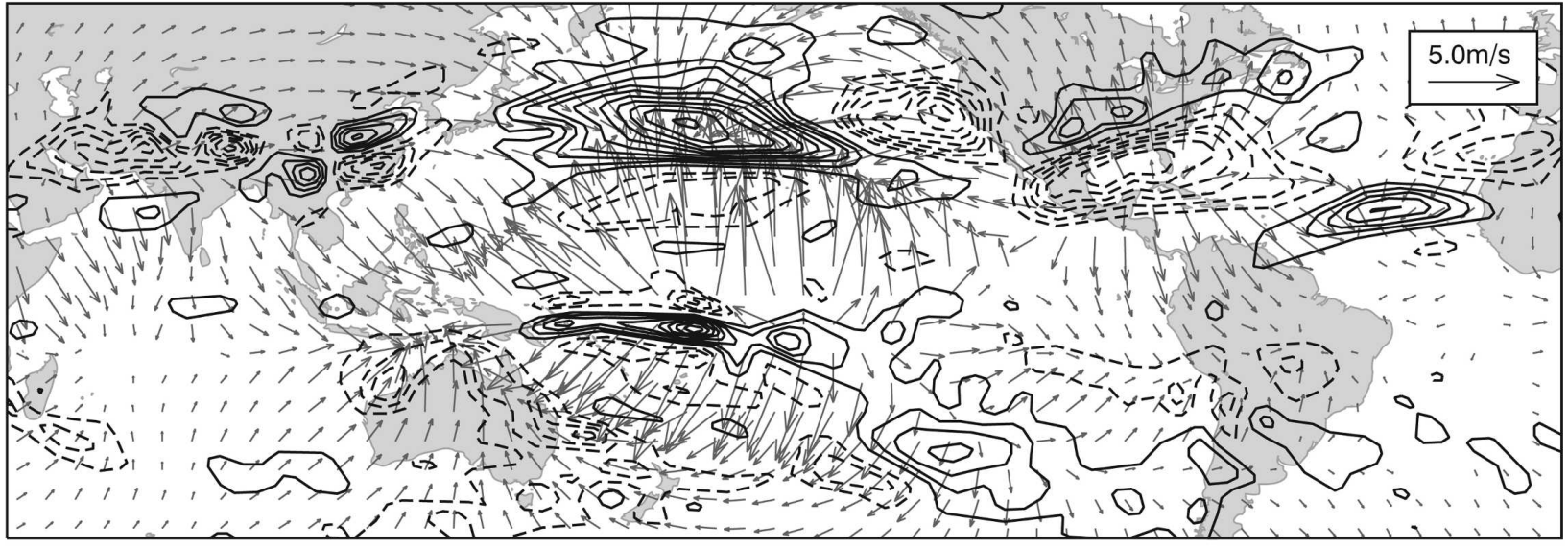

(c) High NAO-CNTL: 200hPa divergent wind and Rossby wave source (DJFM 1982-2001)

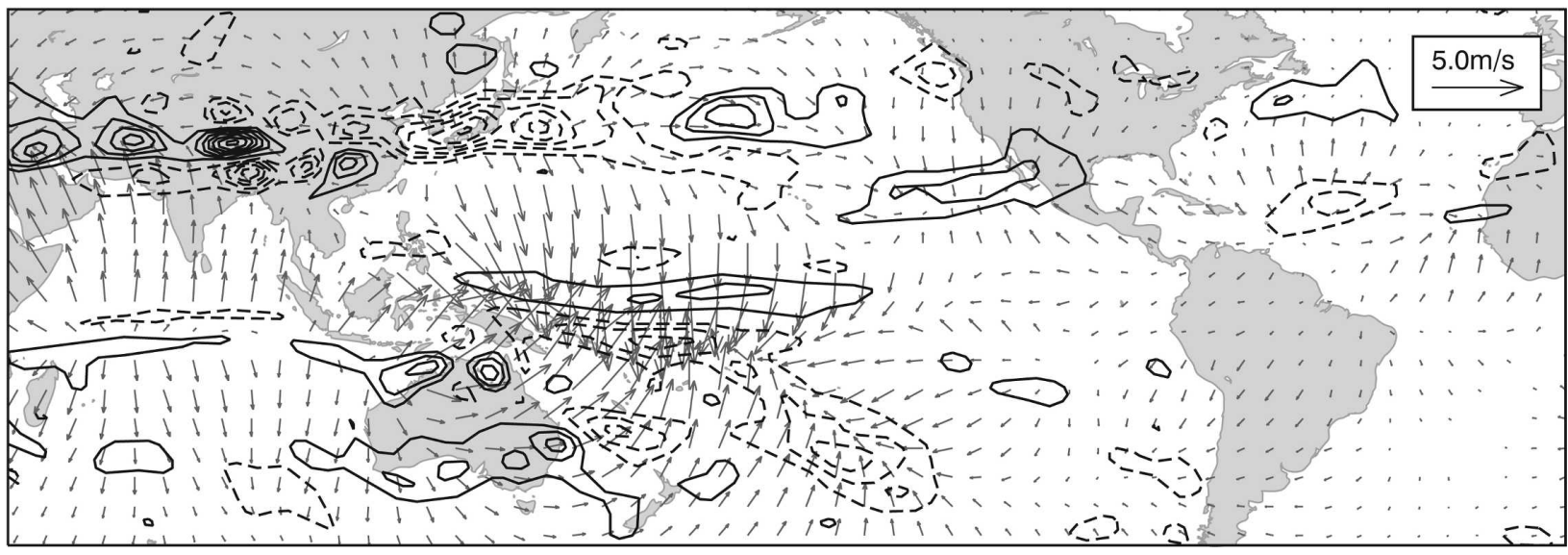

FIG. 9. Divergent wind $\left(\mathrm{m} \mathrm{s}^{-1}\right.$ ) and Rossby wave source (shading in $10^{-10} \mathrm{~s}^{-2}$ ) at $200 \mathrm{hPa}$ : (a) control integration, (b) difference between the sensitivity experiment with tropical diabatic temperature forcing associated with low NAO months and the control integration, and (c) difference between the experiment with tropical diabatic temperature forcing associated with high NAO months and the control integration. A reference arrow for the divergent wind is given in the upper-right corner of the graphs. 
(a) Difference of SST Variability:

1982-2001 minus 1962-1981 (ERA-40)

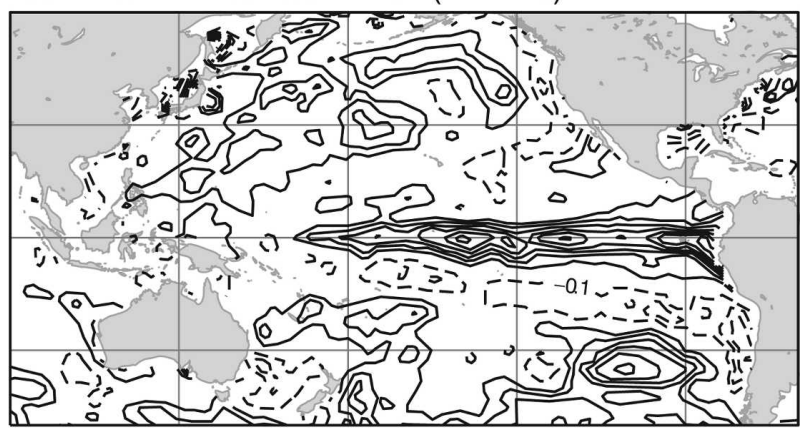

(b) Difference of SLP Variability:

1982-2001 minus 1962-1981 (ERA-40)

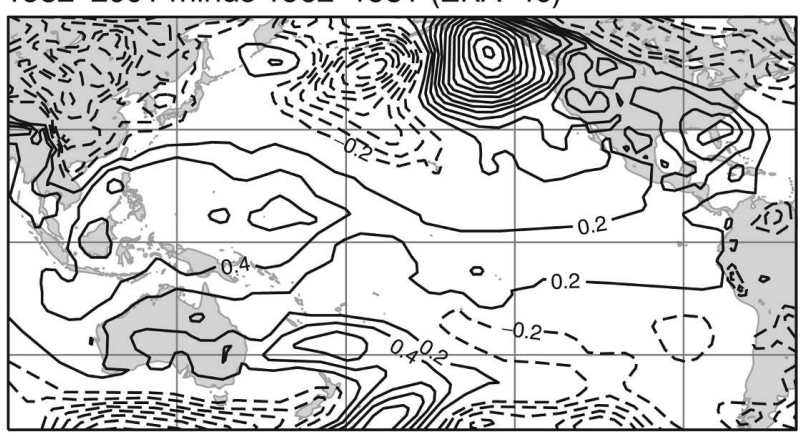

(c) Difference of SLP Variability:

1982-2001 minus 1962-1981 (Model)

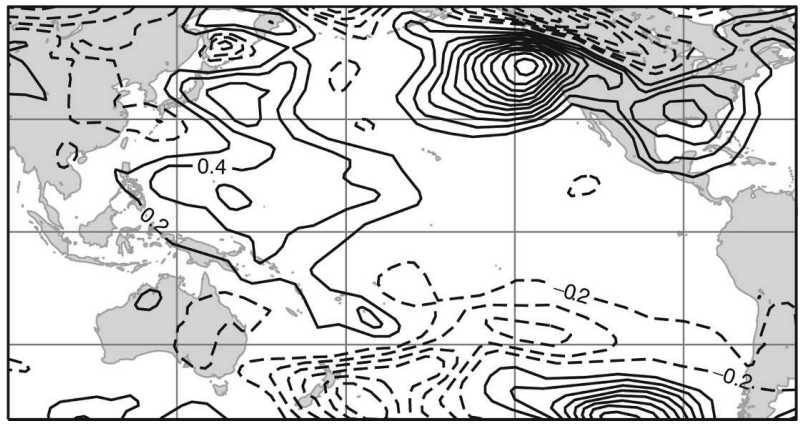

FIG. 10. Difference of the standard deviation for (a) sea surface temperature (K) and (b), (c) sea level pressure (in $\mathrm{hPa}$ ) between the period 1982-2001 and 1962-81. Results are based on wintertime (DJFM) data from (a), (b) ERA-40 and (c) the unforced model integration.

lation (Darwin, Australia, and Tahiti). A similar result is found for the unperturbed integration with ERA-40 SSTs used as lower boundary condition (Fig. 10c), suggesting that the Southern Oscillation index is not necessarily a reliable measure for detecting changes in ENSO-related SST variability. A more detailed analysis of the realism of the increase in ENSO-related SST variability, which goes beyond the scope of the present study, would clearly be desirable.

\section{e. Model response to globally specified forcing}

Figure 11 shows the model response to the globally specified diabatic heating associated with the positive and the negative NAO in the control run (1982-2001). The model response is quite similar in both sets of runs, 1982-2001 and 1962-81, again indicating the robustness of the model response. Nevertheless, over the North Atlantic sector, the model response has little resemblance to the NAO (see Fig. 1). This point is further illustrated by the pdfs (Figs. 6c,f), which show no evidence of a systematic displacement from the unperturbed runs in response to the NAO-related, global diabatic forcing. To help understand the globally forced case, Fig. 12 shows the effect of linearly summing the tropically driven model response shown in Fig. 8 to the model response driven by the local North Atlantic diabatic heating shown in Fig. 5. Clearly, the linear sum agrees well with the globally forced model response (Fig. 11). Since the tropically forced model response does indeed project on to the NAO, it follows that the failure of the globally forced case to project on the $\mathrm{NAO}$ is because of the additional diabatic forcing over the North Atlantic region in the global specification. Furthermore, in the globally forced case, the local diabatic feedback from the NAO over the North Atlantic is being included at least twice: once because in the tropically forced case, the model computes its own diabatic forcing associated with the NAO over the North Atlantic, and twice because the globally specified forcing already includes the NAO-related diabatic forcing local to the North Atlantic region. Furthermore, the sign of the NAO used to specify the forcing over the North Atlantic is the same as being excited in the tropically forced experiment. These issues serve to complicate the interpretation of the globally forced case. The results show, nevertheless, that the dynamical response to extratropical diabatic heating can significantly modify a tropically forced signal.

\section{Summary and discussion}

We began section 3 by using a composite analysis to describe the diabatic forcing for the local temperature tendency that is associated with the NAO in the ECMWF model. Above the planetary boundary layer, we found that the diabatic forcing associated with the NAO is dominated by the latent heat release due to precipitation (i.e., convection plus large scale), whereas in the boundary layer itself, the diabatic forcing is dominated by vertical diffusion (in particular, the sensible heat flux from the ocean). Over the North Atlantic, we found that heating anomalies associated with precipita- 
(a) Z500 Difference:

High NAO-Control (Dec-Mar 1962-1981)

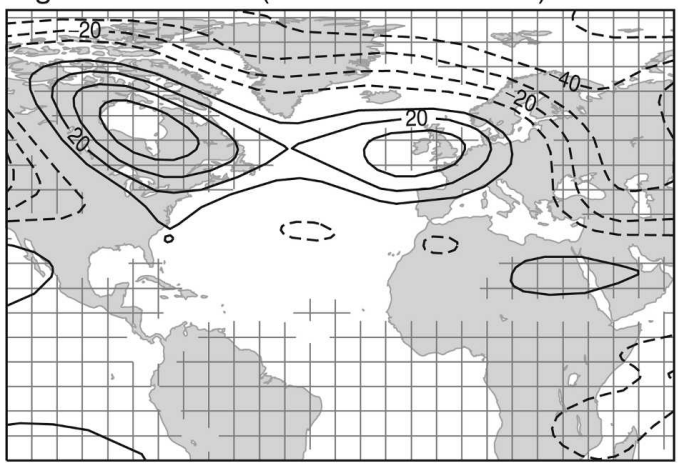

(c) Z500 Difference:

High NAO-Control (Dec-Mar 1982-2001)

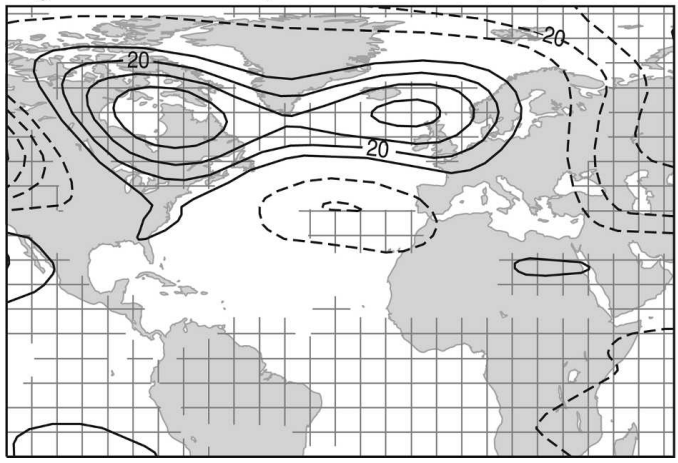

(b) Z500 Difference:

Low NAO-Control (Dec-Mar 1962-1981)

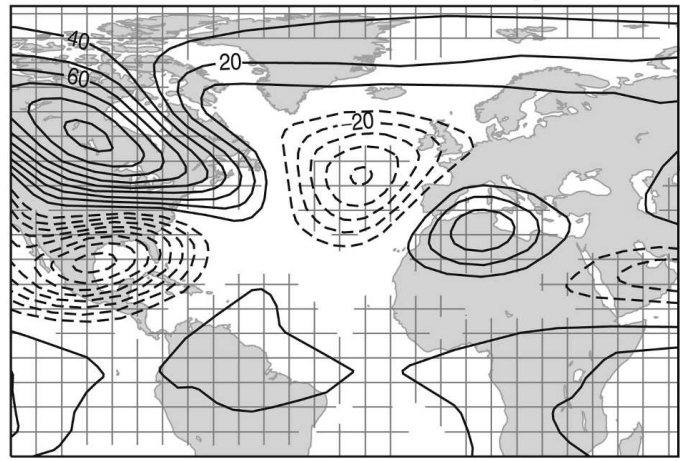

(d) Z500 Difference:

Low NAO-Control (Dec-Mar 1982-2001)

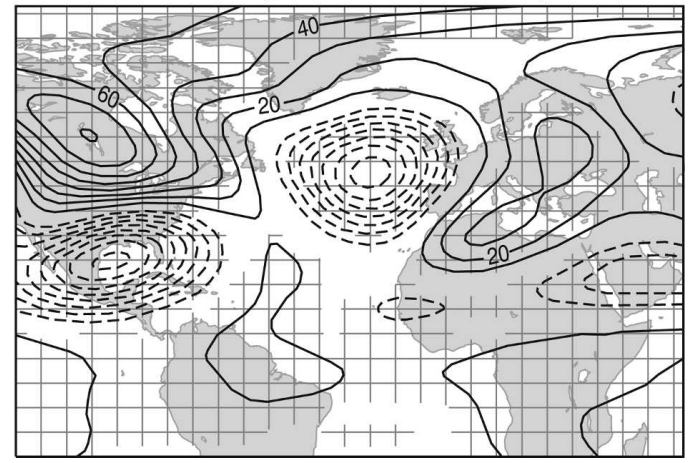

FIG. 11. Same as in Fig. 5, but for globally specified NAO-related diabatic heating.

tion tend to occur downstream of anomalies of the same sign in heat flux (and evaporation) from the ocean, suggesting that the latter feed the former (see also DeWeaver and Nigam 2000). Both sets of anomalies also shift with the NAO so that there is enhanced (reduced) heat loss from the ocean where the westerly winds are strengthened (weakened) and corresponding enhanced (reduced) precipitation heating where the storm track is strengthened (weakened).

To understand how the NAO-related diabatic forcing might feed back on to the NAO, we described experiments in which the diabatic forcing associated with the $\mathrm{NAO}$, and diagnosed from the control run, is applied as an additional, time-independent forcing to the temperature equation in the ECMWF model. The model response to the NAO-related diabatic heating over the North Atlantic region is suggestive of a weak negative feedback on the monthly mean NAO, although the centers of action in the model response are shifted from those of the NAO, and the model response is baroclinic in structure compared to the equivalent-barotropic nature of the NAO itself.

The starting point for the work presented here was the conclusion reached by Hoskins and Valdes (1990) that the latent and sensible heating associated with the climatological storm track acts as a positive feedback such as to "self-sustain" the climatological storm track. We noted in the introduction that the variability of the NAO is associated with major shifts of the storm track (e.g., Rogers 1990), and the question arose as to whether the mechanism identified by Hoskins and Valdes (1990) acts to self-sustain the storm track in the different phases of the NAO. Our results show that in the ECMWF model, at least, this self-sustaining mechanism does not operate for the NAO, since the feedback from the diabatic forcing associated with shifts in the storm track is, if anything, negative (Fig. 5). Despite these discouraging results concerning the role of the selfsustaining mechanism in the dynamics of the NAO, it should be remembered that latent heat release due to precipitation can be a potent force in amplifying middle-latitude storms (Wernli and Davies 1997) and hence may play an indirect role in the dynamics of the NAO by modifying the eddy fluxes (particularly the eddy flux of westerly momentum) that are believed to be important in sustaining the different phases of the NAO (see Thompson et al. 2003).

Our results raise questions concerning the ability of 
(a) Z500 Difference:

High NAO-Control (Dec-Mar 1962-1981)

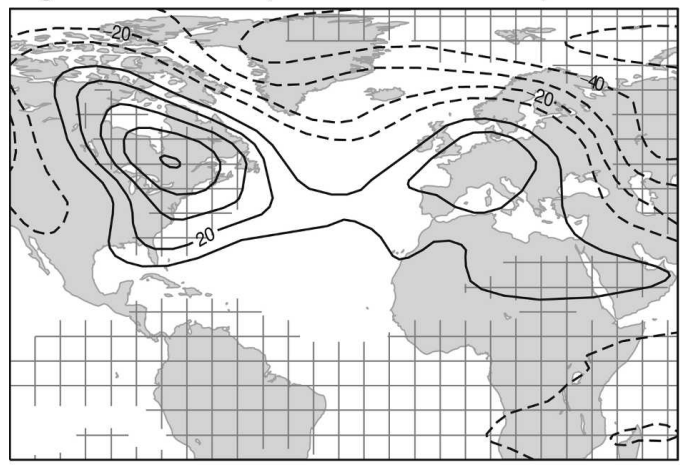

(c) Z500 Difference:

High NAO-Control (Dec-Mar 1982-2001)

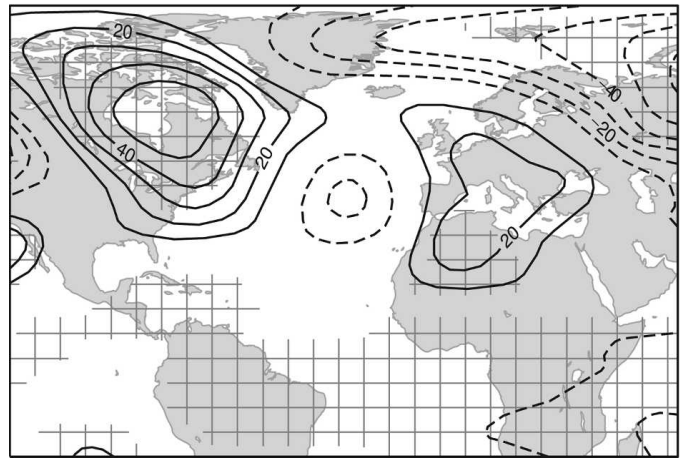

(b) Z500 Difference:

Low NAO-Control (Dec-Mar 1962-1981)

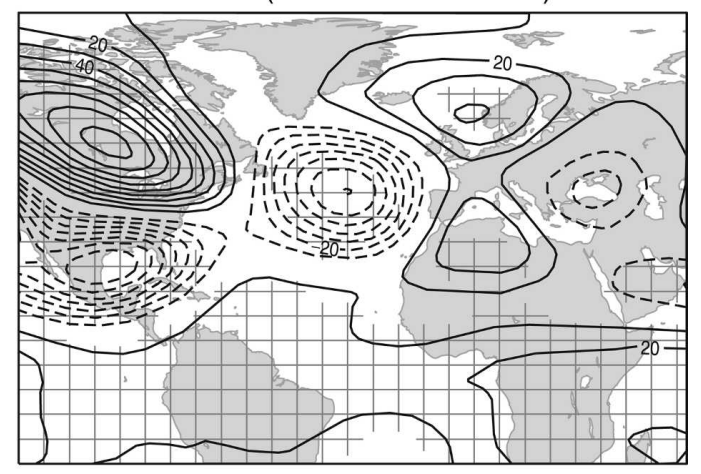

(d) Z500 Difference:

Low NAO-Control (Dec-Mar 1982-2001)

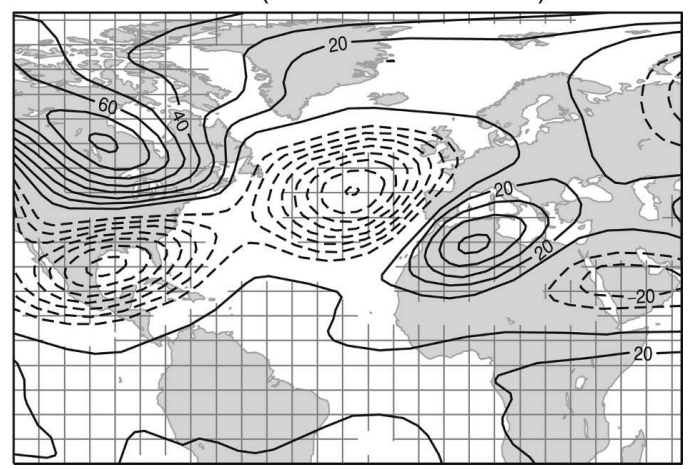

FIG. 12. Same as in Fig. 11, but for the combined response of the two experiments with tropical-only and North Atlantic-only forcing.

the simple GCM used by Peterson et al. (2002) to reproduce, in an ensemble mean sense, the past time history of the winter NAO, and suggest that the success of their model is not because of a positive feedback from the diabatic forcing associated with the NAO, as suggested by these authors. A complication in their study is that the empirical forcing used to force the model does not apply simply to the temperature equation, but also to the equations for vorticity, divergence, and surface pressure as well [see Greatbatch et al. (2003) for a discussion of the complications that can result from this]. A particular weakness of the model is that it has a flat bottom, with the consequence that information about the presence of mountain ranges must also be present in the model forcing. Since the forcing associated with mountain ranges is flow dependent, it is possible that the success of the Peterson et al. study in reproducing the time history of the observed NAO is not because of a positive feedback from the NAO-related diabatic heating, but rather is because the model uses a flat bottom.

A feature of our model results is the importance of the signal emanating from the tropical Pacific, particu- larly the evidence that in the model, diabatic warming (cooling) east (west) of the date line leads to an increase in the frequency of occurrence of the negative (positive) phase of the NAO on monthly time scales. The association of the negative NAO with warm conditions in the tropical Pacific is broadly consistent with the composite analysis of Fraedrich and Müller (1992), and the modeling studies of Merkel and Latif (2002), Mathieu et al. (2004), and Pohlmann and Latif (2005). Brönnimann et al. (2004) have also suggested a persistent El Niño, with an atmospheric teleconnection pattern similar to our negative NAO case, as an explanation for the major climate anomaly of 1940-42, particularly the exceptionally cold winter of 1941/42 in European Russia. By analyzing historical sea level pressure (SLP) data for the period 1873-1995, PozoVázquez et al. (2001), on the other hand, found no statistically significant SLP response in the North Atlantic for El Niño events, whereas La Niña events are associated with the positive phase of the NAO. Moreover, Lin et al. (2005) have argued for a connection between convection anomalies in the tropical Pacific and the positive NAO that does not appear to be con- 
sistent with our results. A possible explanation for these discrepancies is that the impact of ENSO on the Euro-Atlantic sector is not robust, and might vary on interdecadal time scales (van Loon and Madden 1981; Rogers 1984; Greatbatch et al. 2004). As pointed out by Sterl et al. (2006, manuscript submitted to Climate Dyn.), however, there is no statistical evidence from observational data that ENSO teleconnections undergo secular changes (i.e., the observed changes are consistent with what can be expected to occur just by chance).

We believe that our results provide some insight into the controversy surrounding the link between ENSO and the atmospheric circulation in the North Atlantic region. First, we have provided evidence that El Niñoand La Niña-type conditions in the tropical Pacific contributed to forcing the negative and positive phases of the NAO in the unperturbed (control) run for the period 1982-2001. We also showed that the same link is missing from the unperturbed model run for the period 1962-81, suggesting that there are interdecadal episodes, for example, 1982-2001 in the ECMWF model, when the tropical Pacific does force the NAO, and other episodes, for example, 1962-1981 in the ECMWF model, when the link with the tropical Pacific is broken. These results support those observational studies cited above that argue that the impact of ENSO on the NAO changes on interdecadal time scales. We have argued that in the model, the difference between the 1962-81 and 1982-2001 periods is not because of changes in the extratropical flow regime, but rather because of changes in the tropical forcing. We suggested that in the model, this may be because of interdecadal changes in the amplitude of the SST variability in the tropical Pacific, or to do with interdecadal changes in the spatial pattern of the diabatic forcing associated with variability in the tropical Pacific, or both. We also showed that in the ensemble mean, the model response when driven by the globally specified NAO-related diabatic forcing is given to a good approximation by the linear sum of the tropical and locally (North Atlantic) forced model responses, showing that a local NAO-like diabatic forcing can significantly modify tropically driven signals. The fact that substantial systematic errors of the atmospheric circulation-and therefore erroneous diabatic heating-are still present in state-of-the-art atmospheric models in the Northern Hemisphere extratropics (e.g., Jung 2005; Boyle 2006) only adds to the difficulty of realistically simulating the ENSO-related teleconnections, exploited, for example, in seasonal predictions (e.g., Stockdale 2000; Derome et al. 2001).

Acknowledgments. RJG receives support from the Canadian CLIVAR Research Network funded by
NSERC and CFCAS, and the NSERC/MARTEC/MSC Industrial Research Chair. TJ benefited from discussions with Axel Timmermann, and RLG is grateful to Holger Pohlmann for comments that led to improvements in the manuscript. Constructive comments by two anonymous reviewers were also very helpful in shaping the conclusions of this study. Rob Hine helped improving the quality of the figures.

\section{REFERENCES}

Boyle, J. S., 2006: Upper level atmospheric stationary waves in the twentieth century climate of the Intergovernmental Panel on Climate Change simulations. J. Geophys. Res., 111, D14101, doi:10.1029/2005JD006612.

Branstator, G., 1985: Analysis of general circulation model seasurface temperature anomaly simulations using a linear model. Part I: Forced solutions. J. Atmos. Sci., 42, 2225-2241.

__ 1992: The maintenance of low-frequency atmospheric anomalies. J. Atmos. Sci., 49, 1924-1945.

Brönnimann, S., J. Luterbacher, J. Staehelin, T. M. Svendby, G. Hansen, and T. Svense, 2004: Extreme climate of the global troposphere and stratosphere in 1940-42 related to El Nino. Nature, 431, 971-974.

Cassou, C., L. Terray, J. W. Hurrell, and C. Deser, 2004: North Atlantic winter climate regimes: Spatial asymmetry, stationarity with time, and oceanic forcing. J. Climate, 17, 10551068.

Cayan, D. R., 1992: Latent and sensible heat flux anomalies over the northern oceans: Driving the sea surface temperature. $J$. Phys. Oceanogr., 22, 859-881.

Czaja, A., A. W. Robertson, and T. Huck, 2003: The role of Atlantic ocean-atmosphere coupling in affecting North Atlantic Oscillation variability. The North Atlantic Oscillation, Geophys. Monogr., Vol. 134, Amer. Geophys. Union, 147-172.

Derome, J., and Coauthors, 2001: Seasonal predictions based on two dynamical models. Atmos.-Ocean, 39, 485-501.

DeWeaver, E., and S. Nigam, 2000: Zonal-eddy dynamics of the North Atlantic Oscillation. J. Climate, 13, 3893-3914.

_ and 2002: Linearity in ENSO's atmospheric response? J. Climate, 15, 2446-2461.

Evans, K. J., and R. X. Black, 2003: Piecewise tendency diagnosis of weather regime transitions. J. Atmos. Sci., 60, 1941-1957.

Feldstein, S. B., and S. Lee, 1998: Is the atmospheric zonal index driven by an eddy feedback? J. Atmos. Sci., 55, 3077-3086.

Fiorino, M., 2004: A multi-decadal daily sea-surface temperature and sea-ice concentration data set for the ERA-40 reanalysis. ECMWF ERA-40 Project Report Series, No. 12, European Centre for Medium-Range Weather Forecasts, Shinfield Park, Reading, United Kingdom, 22 pp. [Available online at http://www.ecmwf.int/publications.]

Fraedrich, K., and K. Müller, 1992: Climate anomalies in Europe associated with ENSO extremes. Int. J. Climatol., 12, 25-31.

Gill, A. E., 1980: Some simple solutions for heat-induced tropical circulation. Quart. J. Roy. Meteor. Soc., 106, 447-462.

Greatbatch, R. J., 2000: The North Atlantic Oscillation. Stochastic Environ. Res. Risk Assess., 14, 213-242. 
$\longrightarrow$, H. Lin, J. Lu, K. A. Peterson, and J. Derome, 2003: Tropical/ extratropical forcing of the AO/NAO: A corrigendum. Geophys. Res. Lett., 30, 1738, doi:10.1029/2003GL017406.

— , J. Lu, and K. A. Peterson, 2004: Non-stationary impact of ENSO on Euro-Atlantic winter climate. Geophys. Res. Lett., 31, L02208, doi:10.1029/2003GL018542.

Hantel, M., and H.-R. Baader, 1978: Diabatic heating climatology of the zonal atmosphere. J. Atmos. Sci., 35, 1180-1189.

Hoskins, B. J., and P. J. Valdes, 1990: On the existence of storm tracks. J. Atmos. Sci., 47, 1854-1864.

Hurrell, J. W., 1995a: An evaluation of the transient eddy forced vorticity balance during northern winter. J. Atmos. Sci., 52, 2286-2301.

- 1995b: Decadal trends in the North Atlantic Oscillation: Regional temperatures and precipitation. Science, 269, 676679.

—_, Y. Kushnir, G. Ottersen, and M. Visbeck, 2003: An overview of the North Atlantic Oscillation. The North Atlantic Oscillation, Geophys. Monogr., Vol. 134, Amer. Geophys. Union, 1-35.

Jung, T., 2005: Systematic errors of the atmospheric circulation in the ECMWF forecasting system. Quart. J. Roy. Meteor. Soc., 131, 1045-1073.

- - and A. M. Tompkins, 2003: Systematic errors in the ECMWF forecasting system. Tech. Rep. 422, ECMWF, Shinfield Park, Reading, United Kingdom, 72 pp.

Kucharski, F., F. Molteni, and A. Bracco, 2006: Decadal interactions between the western tropical Pacific and the North Atlantic Oscillation. Climate Dyn., 26, 79-91.

Kushnir, Y., W. A. Robinson, I. Bladé, N. M. J. Hall, S. Peng, and R. Sutton, 2002: Atmospheric GCM response to extratropical SST anomalies: Synthesis and evaluation. J. Climate, 15, 2233-2256.

Latif, M., K. Arpe, and E. Roeckner, 2000: Oceanic control of decadal North Atlantic sea level pressure variability in winter. Geophys. Res. Lett., 27, 727-730.

Li, S., M. P. Hoerling, S. Peng, and K. M. Weickmann, 2006: The annular response to tropical Pacific SST forcing. J. Climate, 19, 1802-1819.

Li, Z. X., and S. Conil, 2003: Transient response of an atmospheric GCM to North Atlantic SST anomalies. J. Climate, 16, 3993 3998.

Lin, H., J. Derome, and G. Brunet, 2005: Tropical Pacific link to the two dominant patterns of atmospheric variability. Geophys. Res. Lett., 32, L03801, doi:10.1029/2004GL021495.

Madden, R., and P. R. Julian, 1971: Detection of a 40-50 day oscillation in the zonal wind in the tropical Pacific. J. Atmos. Sci., 28, 702-708.

Mathieu, P.-P., R. T. Sutton, B. Dong, and M. Collins, 2004: Predictability of winter climate over the North Atlantic European region during ENSO events. J. Climate, 17, 19531974.

Mehta, V. M., M. J. Saurez, J. Manganello, and T. L. Delworth, 2000: Ocean influence on the North Atlantic Oscillation and associated Northern Hemisphere climate variations. Geophys. Res. Lett., 27, 121-124.

Merkel, U., and M. Latif, 2002: A high resolution AGCM study of the El Nino impact on the North Atlantic/European sector. Geophys. Res. Lett., 29, 1291, doi:10.1029/2001GL013726.

Peterson, K. A., R. J. Greatbatch, J. Lu, H. Lin, and J. Derome,
2002: Hindcasting the NAO using diabatic forcing of a simple AGCM. Geophys. Res. Lett., 29, 1336, doi:10.1029/ $2001 \mathrm{GL} 014502$.

_ J. Lu, and R. J. Greatbatch, 2003: Evidence of nonlinear dynamics in the eastward shift of the NAO. Geophys. Res. Lett., 30, 1030, doi:10.1029/2002GL015585.

Pohlmann, H., and M. Latif, 2005: Atlantic versus Indo-Pacific influence on Atlantic-European climate. Geophys. Res. Lett., 32, L05707, doi:10.1029/2004GL021316.

Pozo-Vázquez, D., M. J. Esteban-Parra, F. S. Rodrigo, and Y. Castro-Diez, 2001: The association between ENSO and winter atmospheric circulation and temperature in the North Atlantic region. J. Climate, 14, 3408-3420.

Quadrelli, R., and J. M. Wallace, 2002: Dependence of the structure of the Northern Hemisphere annular mode on the polarity of ENSO. Geophys. Res. Lett., 29, 2132, doi:10.1029/ 2002 GL015807.

Rayner, N. A., D. E. Parker, E. B. Horton, C. K. Folland, L. V. Alexander, D. P. Rowell, E. C. Kent, and A. Kaplan, 2003: Global analyses of sea surface temperature, sea ice and night marine air temperature since the late nineteenth century. $J$. Geophys. Res., 108, 4407, doi:10.1029/2002JD002670.

Reynolds, R. W., N. A. Rayner, T. M. Smith, D. C. Stokes, and W. Wang, 2002: An improved in situ and satellite SST analysis for climate. J. Climate, 15, 1609-1625.

Robinson, W. A., 1991: The dynamics of the zonal index in a simple model of the atmosphere. Tellus, 43A, 295-305.

Rodwell, M. J., 2003: On the predictability of North Atlantic climate. The North Atlantic Oscillation, Geophys. Monogr., Vol. 134, Amer. Geophys. Union, 173-192.

_, D. P. Rowell, and C. K. Folland, 1999: Oceanic forcing of the wintertime North Atlantic Oscillation and European climate. Nature, 398, 320-323.

Rogers, J. C., 1984: The association between the North Atlantic Oscillation and the Southern Oscillation in the Northern Hemisphere. Mon. Wea. Rev., 112, 1999-2015.

_ 1990: Patterns of low frequency monthly sea level variability (1899-1986) and associated wave cyclone frequencies. J. Climate, 3, 1364-1379.

Sardeshmukh, P., and B. J. Hoskins, 1988: The generation of global rotational flow by steady, idealised tropical divergence. $J$. Atmos. Sci., 45, 1228-1251.

Stockdale, T., 2000: An overview of techniques for seasonal forecasting. Stochastic Environ. Res. Risk Assess., 14, 305318.

Thompson, D. W. J., S. Lee, and M. P. Baldwin, 2003: Atmospheric processes governing the Northern hemisphere Annular Mode/North Atlantic Oscillation. The North Atlantic Oscillation, Geophys. Monogr., Vol. 134, Amer. Geophys. Union, 81-112.

Ting, M., and N.-C. Lau, 1993: A diagnostic and modeling study of the monthly mean wintertime anomalies appearing in a 100-year GCM experiment. J. Atmos. Sci., 50, 28452867.

Torrence, C., and G. P. Compo, 1998: A practical guide to wavelet analysis. Bull. Amer. Meteor. Soc., 79, 61-78.

Trenberth, K. E., J. M. Caron, D. P. Stepaniak, and S. Worley, 2002: Evolution of El Niño-Southern Oscillation and global 
atmospheric surface temperatures. J. Geophys. Res., 107, Walker, G. T., 1924: Correlation in seasonal variation of weather, 4065, doi:10.1029/2000JD000298.

Uppala, S., and Coauthors, 2005: The ERA-40 re-analysis. Quart. J. Roy. Meteor. Soc., 131, 2961-3012.

van Loon, H., and R. A. Madden, 1981: The Southern Oscillation. Part I: Global associations with pressure and temperature in Northern Hemisphere winter. Mon. Wea. Rev., 109, 11501162. IX. Mem. Indian Meteor. Dept., 24, 275-332.

Wallace, J. M., and D. S. Gutzler, 1981: Teleconnections in the geopotential height field during the Northern Hemisphere winter. Mon. Wea. Rev., 109, 784-812.

Wernli, H., and H. C. Davies, 1997: A Lagrangian-based analysis of extratropical cyclones. I: The method and some applications. Quart. J. Roy. Meteor. Soc., 123, 467-489. 